\title{
Microsomal and Cytosolic Scaling Factors in Dog and Human Kidney Cortex and Application for In Vitro-In Vivo Extrapolation of Renal Metabolic Clearance ${ }^{\mathbb{S}}$
}

\author{
Daniel Scotcher, Sarah Billington, Jay Brown, Christopher R. Jones, Colin D. A. Brown, \\ Amin Rostami-Hodjegan, and Aleksandra Galetin
}

Centre for Applied Pharmacokinetic Research, University of Manchester, Manchester (D.S., A.R.-H., A.G.); Newcastle University, Newcastle (S.B., C.D.A.B.); Biobank, Central Manchester University Hospitals NHS Foundation Trust, Manchester (J.B.); DMPK, Oncology iMed, AstraZeneca R\&D, Alderley Park, Macclesfield (C.R.J.); and Simcyp Limited (a Certara Company), Blades Enterprise Centre, Sheffield (A.R.-H.), United Kingdom

Received January 26, 2017; accepted February 27, 2017

\section{ABSTRACT}

In vitro-in vivo extrapolation of drug metabolism data obtained in enriched preparations of subcellular fractions rely on robust estimates of physiologically relevant scaling factors for the prediction of clearance in vivo. The purpose of the current study was to measure the microsomal and cytosolic protein per gram of kidney (MPPGK and (PPGK) in dog and human kidney cortex using appropriate protein recovery marker and evaluate functional activity of human cortex microsomes. Cytochrome P450 (CYP) content and glucose6-phosphatase (G6Pase) activity were used as microsomal protein markers, whereas glutathione-S-transferase activity was a cytosolic marker. Functional activity of human microsomal samples was assessed by measuring mycophenolic acid glucuronidation. MPPGK was 33.9 and $44.0 \mathrm{mg} / \mathrm{g}$ in dog kidney cortex, and 41.1 and $63.6 \mathrm{mg} / \mathrm{g}$

in dog liver ( $n=17$ ), using P450 content and G6Pase activity, respectively. No trends were noted between kidney, liver, and intestinal scalars from the same animals. Species differences were evident, as human MPPGK and CPPGK were 26.2 and $53.3 \mathrm{mg} / \mathrm{g}$ in kidney cortex $(n=38)$, respectively. MPPGK was 2-fold greater than the commonly used in vitro-in vivo extrapolation scalar; this difference was attributed mainly to tissue source (mixed kidney regions versus cortex). Robust human MPPGK and CPPGK scalars were measured for the first time. The work emphasized the importance of regional differences (cortex versus whole kidney-specific MPPGK, tissue weight, and blood flow) and a need to account for these to improve assessment of renal metabolic clearance and its extrapolation to in vivo.

\section{Introduction}

In vitro drug metabolism data obtained in enriched subcellular fractions such as microsomes or cytosol are commonly scaled using in vitro-in vivo extrapolation (IVIVE) to predict clearance in vivo (Houston and Galetin, 2008; Gertz et al., 2010; Nishimuta et al., 2014).

This work was supported by a PhD studentship from the Biotechnology and Biological Sciences Research Council UK [Grant BB/J500379/1] and AstraZeneca, Cambridge, UK.

Part of this work was previously presented as a poster presentation at the 2015 American Association of Pharmaceutical Scientists annual meeting (Oct. 25-29, 2015, Orlando, FL).

${ }^{1}$ Current affiliation (S.B.): Department of Pharmaceutics, University of Washington, Seattle, Washington.

${ }^{2}$ Current affiliation (C.R.J.): Heptares Therapeutics Limited, BioPark, Welwyn Garden City, Hertfordshire, UK.

https://doi.org/10.1124/dmd.117.0755542.

S This article has supplemental material available at dmd.aspetjournals.org.

This approach relies on robust estimates of physiologically relevant scaling factors, including the protein content of the subcellular fraction in the tissue of interest. Although liver scaling factors have been well characterized [e.g., microsomal (MPPGL) and cytosolic (CPPGL) protein per gram of liver] for human and several preclinical species (Houston, 1994; Barter et al., 2007; Smith et al., 2008; Cubitt et al., 2011), fewer data have been reported for extrahepatic tissues, such as the kidney (Gill et al., 2012; Scotcher et al., 2016a,b). Notably, data are completely lacking for microsomal (MPPGK) and cytosolic (CPPGK) protein per gram of kidney in preclinical species. Although several studies have reported microsomal protein yields for rat kidney, with some also reporting the corresponding data for liver, none of these reports stated clearly whether the protein recovery was estimated and accounted for (Jakobsson, 1974; Litterst et al., 1975; Sausen and Elfarra, 1990; Orellana et al., 2002). In addition, no data exist for CPPGK in humans, and an estimate of cytosolic protein content of liver is currently used as a surrogate for IVIVE (Säll et al., 2012; Nishimuta et al., 2014).

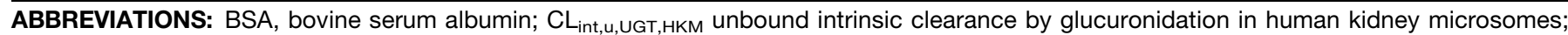
$\mathrm{CL}_{h, \text { met,UGT }}$, hepatic glucuronidation clearance; $C L_{R \text {,met }}$ renal metabolic clearance; $C L_{R, \text { met,UGT }}$ renal glucuronidation clearance; $C L_{U G T}$, overall glucuronidation clearance; CMFT, Central Manchester University Hospitals-NHS Foundation Trust; CPPGK, cytosolic protein per gram of kidney; CPPGL, cytosolic protein per gram liver; $f_{\mathrm{u}}$, fraction unbound; G6Pase, glucose-6-phosphatase; GST, glutathione-S-transferase; HNF, hepatocyte nuclear factors; HKM, human kidney microsome; IVIVE, in vitro-in vivo extrapolation; LC-MS/MS, liquid chromatography-mass spectrometry; MPPGI, microsomal protein per gram intestine; MPPGK, microsomal protein per gram of kidney; MPPGL, microsomal protein per gram of liver; PBS, phosphate-buffered saline; $P_{i}$, inorganic phosphate; $Q_{h} / Q_{R}$, hepatic/renal blood flow; S9, $9000 \mathrm{~g}$ supernatant; UGT, uridine $5^{\prime}$-diphospho-glucuronosyltransferase. 
The MPPGK values for humans range from 5.3 to $32.0 \mathrm{mg} / \mathrm{g}$ of kidney (data based on four literature reports, 23 donors, and different kidney regions), with weighted (by donor number) mean of $13.6 \mathrm{mg} / \mathrm{g}$ of kidney. Several differences in the designs of these studies are evident, for example, selection of microsomal protein marker and the region of kidney used (cortex, medulla, or mixed). It is therefore challenging to distinguish the contribution of true biologic variability and specific interstudy differences from the reported MPPGK values and to establish the most appropriate value to apply as a scaling factor, as summarized in Fig. 1. A value of $12.8 \mathrm{mg} / \mathrm{g}$ of kidney (based on five donors) is the most commonly used scalar for IVIVE of renal drug metabolism data (Scotcher et al., 2016a, b). The region of kidney used to obtain this commonly used scalar is unclear (Al-Jahdari et al., 2006). More recently, MPPGK data for mixed kidney have been reported (i.e., cortex and medulla) (Knights et al., 2016). Combining the data from these two studies resulted in a weighted mean MPPGK of $11.1 \mathrm{mg} / \mathrm{g}$ of kidney.

Kidney samples from mixed regions are also used for preparation of commercially available kidney microsomes (M. Farooq, XenoTech Ltd, Kansas City, KS). Use of mixed kidney microsomes for IVIVE of renal drug metabolism is supported by a recent study indicating that differences in uridine $5^{\prime}$-diphospho-glucuronosyltransferase (UGT) activity between microsomes prepared from the cortex or medulla are reduced when data are normalized for UGT protein abundance (Knights et al., 2016). This approach does not take into consideration other differences between the cortex and medulla, such as content of endoplasmic reticulum, tissue weight, and blood flows. More specifically, the cortex represents approximately $68 \%$ of kidney weight but receives about $80 \%$ of renal blood flow (Lerman et al., 1996; Vallée et al., 2000). Therefore, application of in vitro data obtained from mixed kidney microsomes in the well-stirred kidney model (often applied) may result in inaccurate IVIVE of renal metabolic clearance $\left(\mathrm{CL}_{\mathrm{R}, \mathrm{met}}\right)$. This may be especially pertinent if data are generated to inform parameters of more mechanistic kidney physiologically based models that account for regional differences. Improved confidence in the IVIVE of metabolism by the kidney will increase the accuracy of predicting overall metabolic clearance, despite its generally smaller role compared with hepatic metabolism.

Measurement of microsomal or cytosolic protein contents requires the use of markers of the subcellular fraction of interest. Such markers are used in a quantitative manner to correct for any protein losses during centrifugation. Cytochrome P450 (CYP) content is frequently used as a marker for liver microsomal protein (Barter et al., 2008) but may not be suitable for the kidney as a result of the lower CYP content in this organ (Litterst et al., 1975; Song et al., 2015); therefore, alternative markers, such as glucose-6-phosphatase (G6Pase) and NADPH cytochrome c reductase activity are preferred (Scotcher et al., 2016b). The activities of glutathione-S-transferase (GST) and alcohol dehydrogenase have been reported in the literature for estimation of the cytosolic protein content of human liver (Cubitt et al., 2011); however, a more thorough assessment of the suitability of these enzymes as cytosolic protein markers for kidney is currently lacking.

The aim of this study was to characterize the microsomal and cytosolic protein content, as well as the functional activity, of kidney cortex samples from dogs and humans. CYP content and G6Pase activity were assessed as markers to measure microsomal protein recovery in dog kidney cortex and liver. In addition, the use of fresh and frozen tissue to prepare dog kidney cortex homogenates and microsomes and the impact on subsequent CYP content measurements and MPPGK estimates were assessed. Microsomal protein recovery in dog liver, kidney cortex, and intestine was compared using samples from the same animal donors. After method optimization in dogs, MPPGK and CPPGK were characterized for 38 human kidney cortex samples using G6Pase and GST activity as recovery markers, respectively. Impact of age and

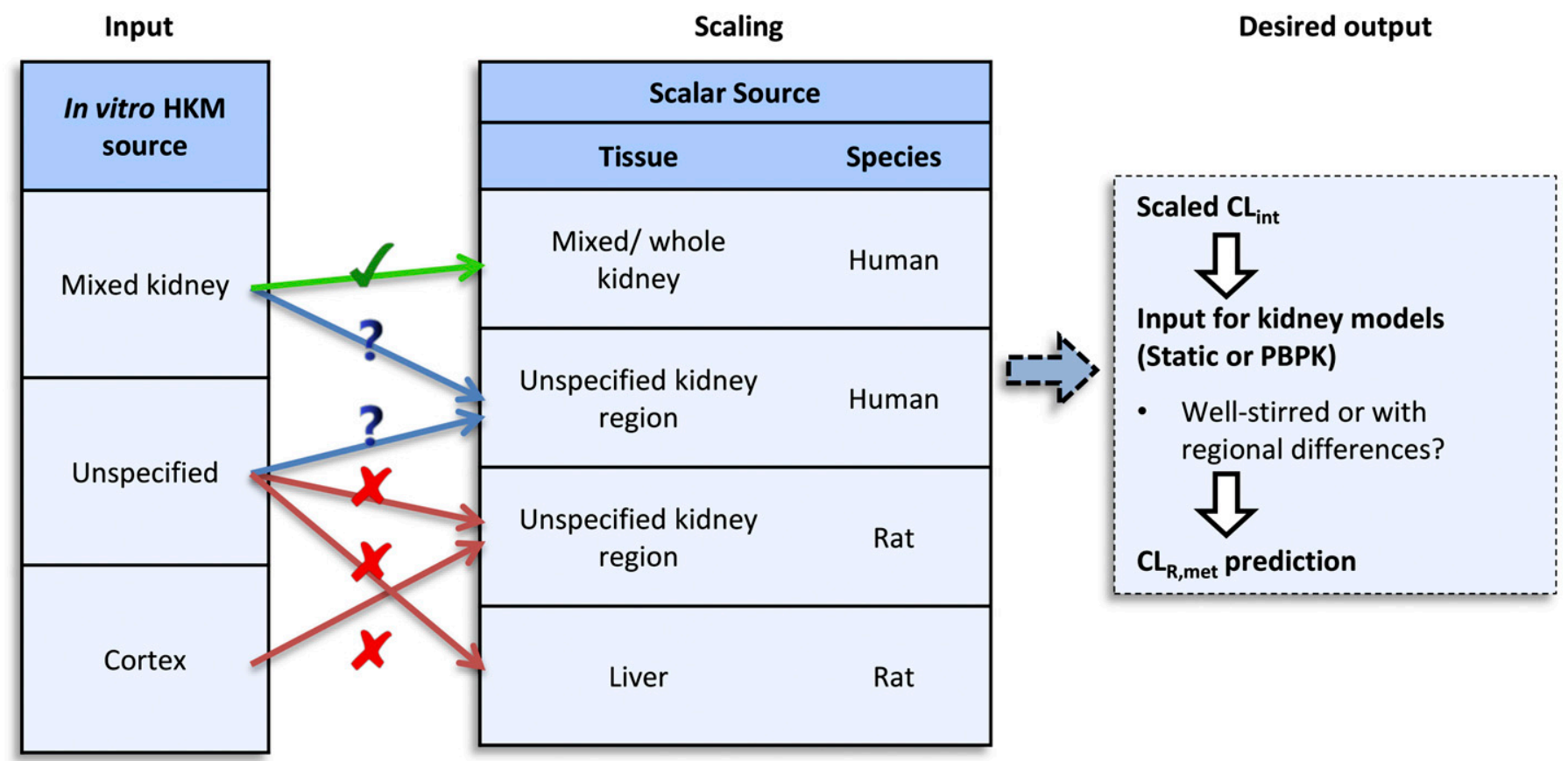

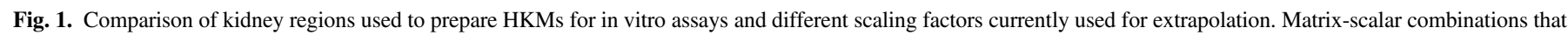

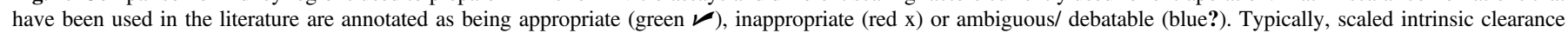

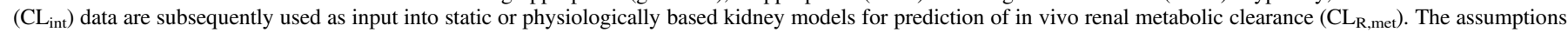

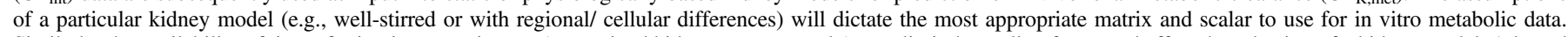

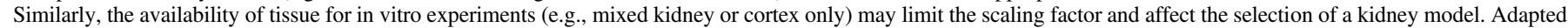
from Fig. 1 in Scotcher et al. (2016a) and references therein, licensed under CC BY 4.0 (http://creativecommons.org/licenses/by/4.0/). 
gender as covariates of MPPGK was investigated for 20 donors for which data were available. For the same subset, selected UGT polymorphisms and functional activity of prepared human kidney cortex microsomes were characterized using mycophenolic acid glucuronidation substrate depletion assay as activity marker. The mycophenolic acid unbound intrinsic clearance by glucuronidation obtained in human kidney cortex microsomes $\left(\mathrm{CL}_{\text {int,u,UGT,HKM }}\right)$ was scaled by both historical MPPGK for the whole kidney and the newly acquired MPPGK data for the kidney cortex to assess the impact of revised scaling factors on predicted renal metabolic clearance.

\section{Materials and Methods}

\section{Isolation of Microsomal Protein from Dog Kidney Cortex}

Reagents. Chemicals were purchased from Sigma-Aldrich (Gillingham, Dorset, UK) unless otherwise specified. Homogenization buffer was phosphatebuffered saline (PBS) with $0.5 \mathrm{mM}$ EDTA, $5 \mathrm{mM}$ histidine, and $0.25 \mathrm{M}$ sucrose, $\mathrm{pH}$ 7.4. Storage buffer was $100 \mathrm{mM}$ Trizma with $0.5 \mathrm{mM}$ EDTA in deionized water, $\mathrm{pH}$ 7.4. CYP assay buffer was $25 \mathrm{mM}$ potassium phosphate buffer, $\mathrm{pH} 7.4$, with $1.5 \% \mathrm{w} / \mathrm{v}$ potassium chloride and $30 \% \mathrm{v} / \mathrm{v}$ glycerol (Fisher Scientific, Loughborough, UK). G6Pase assay buffer was $100 \mathrm{mM}$ BIS-TRIS, pH 6.5. Taussky-Shorr color reagent (Taussky and Shorr, 1953) was $0.18 \mathrm{M}$ ferrous sulfate heptahydrate, $1 \% \mathrm{w} / \mathrm{v}$ ammonium molybdate in $0.5 \mathrm{M}$ sulfuric acid.

Sample Collection and Perfusion. Kidneys and livers from 17 beagle dogs (4 males, 13 females) were obtained from necropsy at AstraZeneca (Alderley Park, Macclesfield, UK) according to institutional guidelines in compliance with national and regional legislation. The age and weights of the dogs ranged from 3.8 to 10.3 years and 19.7 to $20.5 \mathrm{~kg}$, respectively. Liver weights were 315-709 g; kidney weights were $47-89 \mathrm{~g}$. Livers were transferred to the laboratory in PBS on ice; kidneys were transferred in PBS containing $9 \mathrm{U} / \mathrm{ml}$ of heparin on ice. Kidneys were perfused with PBS containing $9 \mathrm{U} / \mathrm{ml}$ of heparin at $37^{\circ} \mathrm{C}$ at $8 \mathrm{ml} / \mathrm{min}$ for $15 \mathrm{~min}$ through the renal artery. All subsequent processes were performed on ice unless specified. Kidneys were cut in half and decapsulated, and each kidney half was blotted to remove excess liquid and weighed. Kidney halves from one kidney were frozen at $-80^{\circ} \mathrm{C}$, and the other kidney was used to prepare homogenate. Pieces of liver $(\sim 10-20 \mathrm{~g})$ were washed in PBS, weighed, and frozen at $-80^{\circ} \mathrm{C}$.

Dog Homogenate and Microsome Preparation. Homogenization and centrifugation methods used for preparation of kidney microsomes vary but generally follow the same core strategy that involves an initial centrifugation of homogenate at around 9000-12,000 g to remove cellular debris and larger organelles, followed by ultra-centrifugation of the resulting supernatant at $100,000-110,000 \mathrm{~g}$ to obtain the microsomal protein pellet (Supplemental Fig. S1). The method applied in the current study, which was consistent with this core strategy, was based on the inhouse method developed for the intestine, with modifications to optimize homogenization of kidney (Hatley et al., 2017).

Frozen dog tissue samples, stored at $-80^{\circ} \mathrm{C}$, were rapidly thawed at $37^{\circ} \mathrm{C}$, washed in PBS, blotted, and weighed. Kidney cortex (2.0-5.0 g) and liver (3.4-4.3 g) were minced with scissors and homogenized with 4 to $5 \mathrm{ml} / \mathrm{g}$ mince of homogenization buffer. Homogenization was initially with a rotor-stator homogenizer (Omni International, Kennesaw, GA) with a $10 \mathrm{~mm} \times 95-\mathrm{mm}$ probe. Bursts of $20 \mathrm{~s}$ with $30 \mathrm{~s}$ rest on ice were used until no intact pieces of tissue mince were apparent on visual assessment. The number of bursts for each sample depended on the starting weight of the minced tissue but required no more than eight bursts for kidney cortex and four bursts for liver. Samples were further homogenized using a VibraCell ultrasonic processor (Sonics \& Materials, Inc., Newtown, CT) for two bursts of $10 \mathrm{~s}$, separated with a $30 \mathrm{~s}$ resting period on ice to prevent excessive heat buildup. Homogenate was filtered through $170-\mu$ m nylon mesh (Plastok Associates, Birkenhead, Merseyside, UK). Homogenate volumes were measured, and aliquots were stored on ice for analysis. Liver and kidney cortex homogenates were centrifuged at $9000 \mathrm{~g}$ at $4^{\circ} \mathrm{C}$ for $15 \mathrm{~min}$ using an Optima LE-80K ultracentrifuge with a type 50.2Ti rotor (Beckman Coulter UK Ltd., High Wycombe, Buckinghamshire, UK). Supernatants were further centrifuged at $105,000 \mathrm{~g}$ at $4^{\circ} \mathrm{C}$ for $70 \mathrm{~min}$. Aliquots of the cytosol were retained. The microsomal pellet was resuspended in storage buffer using a handheld Potter-Elvehjem homogenizer. Samples were stored at $-80^{\circ} \mathrm{C}$.

Microsomal Protein Markers in Dog Samples. Frozen samples were thawed rapidly at room temperature, and kept on ice until used (Pearce et al., 1996). Protein in homogenate, microsomes, and cytosol was determined using a microbicinchoninic acid protein assay kit (Pierce Biotechnology no. 23227; Pierce Biotechnology, Waltham, MA) according to the manufacturer's instructions. Absorbance (562 nm) was measured with a Tecan Safire microplate reader with XFluor4 software (Reading, Berkshire, UK).

The CYP content of homogenate and microsomal samples was measured according to the dithionite difference spectroscopy method of Matsubara et al. (1976). Samples were diluted to $2 \mathrm{mg} / \mathrm{ml}$ in CYP assay buffer and bubbled (about one bubble/s) for $1 \mathrm{~min}$ with carbon monoxide. Then $1 \mathrm{ml}$ of diluted samples were dispensed into each of two semi-microcuvettes (VWR, Radnor, PA), and baseline absorbance spectrum was measured (400-600 nm) using a UV-2401-PC dualbeam spectrophotometer with UVPC software (Shimadzu, Milton Keynes, Buckinghamshire, UK), and $10 \mu \mathrm{l}$ of freshly prepared sodium dithionite ( $200 \mathrm{mg} / \mathrm{ml}$ in CYP assay buffer) was added to the sample cuvette. The sample cuvette was inverted 4 times, left to stand for $4 \mathrm{~min}$, and then the absorbance spectrum measured. CYP content (nmol/mg protein) was calculated using a molar extinction coefficient (A450-490) of 0.104 (Matsubara et al., 1976). Interassay variability of CYP content measurements was assessed by repeat measurements in four batches of homogenates and microsomes from three dogs (i.e., two batches prepared from the same animal).

Various endogenous contaminants, such as methemoglobin, cytochrome $b_{5}$, and cytochrome oxidase, can potentially interfere with CYP content measurements in microsomal samples (Estabrook and Werringloer, 1978; Johannesen and DePierre, 1978; Burke and Orrenius, 1979). Furthermore, during preliminary experiments, broad absorbance peaks were observed at approximately 426 and $430 \mathrm{~nm}$ in homogenate and microsomes, respectively, which may have interfered with the A450 measurements and therefore affected CYP content measurement and MPPGK estimates. It was previously reported that this interference can be limited by chemically reducing the contaminants during the CYP content assay (Estabrook and Werringloer, 1978; Burke and Orrenius, 1979). In the current study, inclusion of $0.25 \mathrm{mM}$ sodium ascorbate and $2.5 \mu \mathrm{M}$ phenazine ethosulfate, reported to reduce methemoglobin (Burke and Orrenius, 1979), did not cause substantial change in the dithionite difference spectra for dog kidney cortex microsomes, although a small shift in the $426-\mathrm{nm}$ peak to $430 \mathrm{~nm}$ was noted (data not shown). Inclusion of NADH and sodium succinate, which are reported to reduce cytochrome $b_{5}$ and cytochrome oxidase (Estabrook and Werringloer, 1978; Burke and Orrenius, 1979), in the CYP content assay buffer caused a change in the spectra of homogenate $(\sim 400-420 \mathrm{~nm})$ and microsomes $(\sim 400-$ $435 \mathrm{~nm}$ ) (Supplemental Fig. S2). As no major change in baseline or peak at $450 \mathrm{~nm}$ was observed, neither the CYP measurements in homogenate and microsome samples nor the estimates of MPPGK were affected. Therefore, the sodium dithionite difference spectra assay as reported in the literature (Matsubara et al., 1976), that is, without modification of buffer constituents, was considered sufficient for estimation of MPPGK in dogs.

The G6Pase activity was measured in duplicate using a spectrophotometric method (Nordlie and Arion, 1966). Homogenate and microsomal protein and glucose-6-phosphate were preincubated separately in G6Pase assay buffer at $37^{\circ} \mathrm{C}$ for $10 \mathrm{~min}$. Homogenate and microsomes $(0.25 \mathrm{mg} / \mathrm{ml})$ were added to the G6P $(1 \mathrm{mM})$ to initiate the reaction, and an aliquot was immediately quenched (3:1) in $20 \%$ trichloroacetic acid on ice $(t=0 \mathrm{~min})$. Additional aliquots were quenched at $5,15,30$, and $60 \mathrm{~min}$. After centrifugation at $4000 \mathrm{rpm}$ for $10 \mathrm{~min}$, samples and phosphorous standards were added in 1:1 ratio to Taussky-Shorr color reagent. Absorbance $(660 \mathrm{~nm})$ was measured with a Tecan Safire plate reader with XFluor4 software. Results were processed with Microsoft Excel. G6Pase activity was expressed as nanomolars of inorganic phosphate $\left(\mathrm{P}_{\mathrm{i}}\right)$ formed per min/mg protein based on the initial linear rate of $\mathrm{P}_{\mathrm{i}}$ formation. Interassay variability for G6Pase activity was assessed by remeasurement of a single set of samples prepared from the kidneys of three different dogs in three separate assays.

\section{Isolation of Microsomal and Cytosolic Protein from Human Kidney Cortex}

Reagents. XenoTech mixed-gender pooled (13 donors) human whole/mixed kidney microsomes (lot. 1410120; 4-methylumbelliferone glucuronidation activity of $105 \mathrm{nmol}$ per $\mathrm{min} / \mathrm{mg}$ of protein) were obtained from Tebu-bio (Peterborough, Cambs, UK). Chemicals were purchased from Sigma-Aldrich (Gillingham, Dorset, UK) unless otherwise specified. Homogenization buffer was $25 \mathrm{mM}$ Trizma, $0.5 \mathrm{mM}$ EDTA, $5 \mathrm{mM}$ histidine, $0.25 \mathrm{M}$ sucrose, $\mathrm{pH}$ 7.4. Trizma was used as an alternative to PBS to reduce background signal in G6Pase assay. Storage buffer, G6Pase assay buffer, and Taussky-Shorr color reagent were 
prepared as described earlier herein for dogs. Mycophenolic acid glucuronidation assay buffer was $0.1 \mathrm{M}$ phosphate buffer containing $3.45 \mathrm{mM} \mathrm{MgCl}_{2}, 1.15 \mathrm{mM}$ EDTA, and $115 \mu \mathrm{M}$ saccharic acid lactone (Kilford et al., 2009).

Sample Collection and Storage. Normal human kidney cortex pieces from nephrectomy patients $(n=20)$, excised from the pole of the kidney contralateral to the tumor site, were obtained by the Biobank, Central Manchester University Hospitals NHS Foundation Trust (CMFT), UK. Kidney cortex pieces were snapfrozen within $1 \mathrm{~h}$ of excision and stored at $-80^{\circ} \mathrm{C}$. Informed consent was obtained from donors. Ethical approval for this research was obtained from National Research Ethics Service (NRES) Committee London, Camberwell St. Giles (REC ref. 13/LO/1896), with samples stored under Human Tissue Authority license.

Human kidney cortex homogenates $(n=18)$ were prepared from renal cortex from healthy kidneys unsuitable for transplant at Newcastle University, obtained under NRES ethical approval with informed consent from the donors. Homogenates from Newcastle University were stored at $-80^{\circ} \mathrm{C}$ until used. No information on the time delay between organ isolation and storage was available.

Homogenate and Microsomal Preparation. A single batch of homogenate and microsomes was prepared for each donor, with the exception of donor CMFT6, for which an initial batch was prepared for use in preliminary experiments; data generated during preliminary experiments were not included in analyses of the main data set. Frozen human kidney cortex samples were rapidly thawed at $37^{\circ} \mathrm{C}$, washed in PBS, blotted dry, and weighed. Finely minced human kidney cortex samples (1.2-6.7 g) were homogenized with 4 to $5 \mathrm{ml} / \mathrm{g}$ of mince of homogenization buffer. Homogenization was initially with a rotor-stator homogenizer (Dremel UK, Middlesex, UK). Bursts of $20 \mathrm{~s}$ with $30 \mathrm{~s}$ rest on ice were used until no intact pieces of kidney cortex mince were apparent upon visual assessment. This typically required three to six bursts, depending on the starting weight of the kidney cortex mince. Samples were further homogenized using an Omni Ruptor 400 Ultrasonic homogenizer (Omni International, Kennesaw, GA) for two bursts of $10 \mathrm{~s}$ each, separated with a $30-\mathrm{s}$ resting period on ice. Homogenate was filtered through 170- $\mu$ m nylon mesh (Plastok Associates). Homogenates from Newcastle University were thawed rapidly at $37^{\circ} \mathrm{C}$ and then kept on ice until use. Total kidney cortex homogenate volumes were measured, and aliquots were stored on ice for analysis.

Human kidney cortex homogenates were centrifuged at $9000 \mathrm{~g}$ at $4^{\circ} \mathrm{C}$ for 15 min using an Optima TLX-120 Ultracentrifuge with an MLA-80 rotor (Beckman Coulter UK Ltd). After removing aliquots for analysis (1 to $2 \mathrm{ml}$, stored on ice), $9000 \mathrm{~g}$ supernatants (S9) were further centrifuged at $105,000 \mathrm{~g}$ at $4^{\circ} \mathrm{C}$ for $70 \mathrm{~min}$. Aliquots of the cytosol were stored on ice for analysis. The microsomal pellet was resuspended in storage buffer using a vortex mixer and pipette. Aliquots were taken for protein content analysis; remaining microsomal samples were stored at $-80^{\circ} \mathrm{C}$

Microsomal and Cytosolic Protein Markers in Human Samples. On the day of microsomal preparation, protein content in homogenate, S9, microsomes, and cytosol was determined in triplicate using a Micro Bicinchoninic Acid Protein Assay Kit (Pierce Biotechnology no. 23227) according to the manufacturer's instructions. Absorbance $(562 \mathrm{~nm})$ was measured with a SpectraMax 190 plate reader (Molecular Devices, Sunnyvale, CA), with BSA used as calibration standard. All activity assays were performed on samples that had undergone four or fewer freeze-thaw cycles. G6Pase activity was measured in duplicate using the spectrophotometric method described earlier herein for the dog samples; absorbance $(660 \mathrm{~nm})$ was measured with a SpectraMax 190 plate reader. Interassay variability was assessed using four batches of human kidney cortex homogenate and microsomes from three kidney cortex samples, for which G6Pase activity was measured twice. Interbatch variability was assessed through preparation of two batches of homogenate and microsomes (donor CMFT6) on different days. Interbatch and interassay variability were compared by measuring G6Pase activities for each batch in two separate assays, with one of these assays common for both batches.

GST activity was measured in human kidney cortex homogenate, microsomes, and cytosol samples using an assay kit (Sigma no. CS0410) according to the manufacturer's instructions with the following modification: samples were initially prepared in $0.1 \mathrm{M}$ sodium phosphate buffer, $\mathrm{pH} 6.5$, with $1 \%$ Triton X-100 (Ji et al., 2002) owing to inadequate volume of sample buffer provided with the assay kit. GST activity was measured using protein concentrations of $10 \mu \mathrm{g} / \mathrm{ml}$ (determined after preliminary optimization experiments using rat kidney samples), with substrate concentrations of 100 and $200 \mu \mathrm{M}$ for 1-chloro-2,4-dinitrobenzene and L-glutathione, respectively. Absorbance $(340 \mathrm{~nm})$ was measured at appropriate time points up to 10 min using a SpectraMax 190 plate reader. Results were processed with Microsoft Excel. GST activity was expressed as nmol/min/mg protein based on the initial linear rate of $\triangle \mathrm{A} 340$, using an extinction coefficient $\left(\Delta \mathrm{A}_{340}\right)$ of $9.6 \mathrm{mM}^{-1} \mathrm{~cm}^{-1}$ for 1-chloro-2,4-dinitrobenzene conjugate.

\section{Estimation of Microsomal and Cytosolic Protein Contents of Tissues}

Various parameters (Table 1), including yields of total protein and microsomal marker in subcellular fractions from a microsomal preparation, as well as the recovery factor of the microsomal protein, were calculated (eq. 1-4). This approach allowed correction for the removal of material as aliquots of homogenate and S9 before differential centrifugation steps when calculating the theoretical yield of the protein marker (eq. 2). The latter represents the marker activity/content if there was a complete recovery of the marker that was present in the homogenate (eq. 2). Actual (eq. 3) and theoretical yield of the marker activity/content in the microsomal fraction obtained from the homogenate were used to calculate MPPGK (eq. 5). In addition, a microsomal or cytosolic protein enrichment factor was calculated based on the marker activity/content of the subcellular fraction relative to that of the homogenate (eq. 6):

$$
\begin{aligned}
& \text { Abs_Prot }{ }_{x}=[\text { Prot }]_{x} \times V_{x, \text { total }} \\
& \text { Yield }_{\text {Marker,Theor }}=\text { Marker }_{\text {Hom }} \times \text { Abs_Prot }_{\text {Hom }} \times \frac{V_{\text {Hom,total }}-V_{\text {Hom,aliquot }}}{V_{\text {Hom,total }}} \\
& \times \frac{V_{S 9, \text { total }}-V_{S 9, \text { aliquot }}}{V_{S 9, \text { total }}} \\
& \text { Yield }_{\text {Marker }, \text { Actual }}=\text { Marker }_{x} \times \text { Abs }_{-} \text {Prot }_{x} \times V_{\text {Mic,total }} \\
& \text { Recovery }_{x}=\frac{\text { Yield }_{\text {Marker }, \text { actual }}}{\text { Yield }_{\text {Marker, }, \text { heor }}} \\
& M P P G K=\frac{\text { Abs_Prot }_{\text {Mic }}}{\text { Recovery }_{\text {Mic }} \times W_{\text {Kid }}} \\
& \text { Enrichment }_{x}=\frac{\text { Marker }_{x}}{\text { Marker }_{\text {hom }}}
\end{aligned}
$$

The preceding equations are applicable for calculation of the cytosolic protein recovery and CPPGK in conjunction with appropriate cytosolic protein markers. GST can be considered a cytosolic marker, with a limitation that some GSTs are also found in the endoplasmic reticulum component of the microsomal fraction (Hayes and Pulford, 1995; Song et al., 2015). In an exploratory assay, substantial GST activity was noted in human kidney cortex microsomes, suggesting that GST activity in human kidney cortex homogenate was attributable to both cytosolic and microsomal isoforms (Supplemental Fig. S3). Therefore, MPPGK for each human kidney donor, estimated using G6Pase activity as microsomal protein marker, was used to account for the GST activity attributable to the microsomal GST in each human kidney cortex homogenate (eq. 7-9). This involved calculating the total microsomal protein and then the microsomal GST activity in the homogenate, which was subtracted from the theoretical GST yield (calculated using eq. 2). This corrected theoretical GST activity yield in homogenate was compared with the actual GST activity yield in the cytosolic fraction (eq. 3) to account for cytosolic protein losses during the fractionation procedure and subsequently CPPGK (eq. 10 and 11).

To ensure that the estimates of MPPGK and CPPGK were physiologically feasible, their combined value was compared with the amount of homogenate protein obtained per gram of kidney cortex for each donor. The combined value should reflect the S9 protein content per gram of kidney cortex. Therefore, the value calculated was expressed as the percent contribution of the $\mathrm{S} 9$ fraction to the overall protein in the homogenate (eq. 12):

$$
\begin{aligned}
& \text { Mic_Prot }{ }_{\text {Hom }}=M P P G K \times W_{\text {Kid }} \\
& \text { Mic_GST Hom }=\text { Mic_Prot } \text { Hom }_{\text {Hom }} \times G S T_{\text {Mic }} \\
& \text { Yield }_{G S T, \text { Theor,corrected }}=\text { Yield }_{G S T, \text { Theor }}-\text { Mic_GST }_{\text {Hom }} \\
& \text { Recovery }_{C y t}=\frac{\text { Yield }_{G S T, \text { actual }}}{\text { Yield }_{G S T, \text { theor,corrected }}} \\
& C P P G K=\frac{\text { Abs_Prot }_{C y t}}{\text { Recovery }_{C y t} \times W_{\text {Kid }}} \\
& \text { S9_contribution }{ }_{\mathrm{Hom}}=\frac{\mathrm{MPPGK}+\mathrm{CPPGK}}{\mathrm{Abs}_{-} \text {Prot }_{\mathrm{Hom} / \mathrm{W}_{\mathrm{Kid}}}} \times 100(\%)
\end{aligned}
$$


TABLE 1

Parameters used in calculation of MPPGK and CPPGK from human and dog kidney cortex samples

\begin{tabular}{|c|c|c|}
\hline Parameter $^{a}$ & Description & Units \\
\hline Abs_Prot $_{\mathrm{x}}$ & Absolute protein yield in homogenate or subfraction $(x)$ & $\mathrm{mg}$ \\
\hline$[\operatorname{Prot}]_{\mathrm{x}}$ & Protein concentration of homogenate or subfraction $(x)$ & $\mathrm{mg} / \mathrm{ml}$ \\
\hline $\mathrm{V}_{\mathrm{x}, \text { total }}$ & $\begin{array}{l}\text { Volume of homogenate or subfraction }(x) \text {, before aliquots are } \\
\text { taken for analysis where applicable }\end{array}$ & $\mathrm{ml}$ \\
\hline $\mathrm{V}_{\mathrm{x}}$, aliquot & Volume of homogenate or subfraction aliquot taken for analysis & $\mathrm{ml}$ \\
\hline Marker $_{\mathrm{x}}$ & $\begin{array}{l}\text { Activity or content of subcellular protein marker in homogenate, } \\
\text { microsome, or cytosol }(x)\end{array}$ & $\begin{array}{c}\mathrm{nmol} / \mathrm{mg} \text { protein }(\mathrm{CYP}) \\
\mathrm{nmol} / \mathrm{min} / \mathrm{mg} \text { protein }(\mathrm{G} 6 \mathrm{Pase}) \\
\mathrm{nmol} / \mathrm{min} / \mathrm{mg} \text { protein }(\mathrm{GST})\end{array}$ \\
\hline $\mathrm{W}_{\text {Kid }}$ & Weight of starting kidney tissue mince & $\mathrm{g}$ \\
\hline Yield $_{\text {Marker, theor }}$ & $\begin{array}{l}\text { Theoretical yield of subcellular protein marker from } \\
\text { homogenate, accounting for aliquot removal }\end{array}$ & $\begin{array}{c}\mathrm{nmol}(\mathrm{CYP}) \\
\mathrm{nmol} / \mathrm{min}(\mathrm{G} 6 \mathrm{Pase}) \\
\mathrm{nmol} / \mathrm{min}(\mathrm{GST})\end{array}$ \\
\hline Yield $_{\text {Marker, actual }}$ & Actual yield of subcellular protein marker from homogenate & $\begin{array}{c}\mathrm{nmol}(\mathrm{CYP}) \\
\mathrm{nmol} / \mathrm{min}(\mathrm{G} 6 \mathrm{Pase}) \\
\mathrm{nmol} / \mathrm{min}(\mathrm{GST})\end{array}$ \\
\hline Recovery $_{X}$ & Percent recovery & $\%$ \\
\hline Enrichment $_{\mathrm{x}}$ & Enrichment factor of subcellular protein $(x)$ & \\
\hline Mic_ Prot $_{\mathrm{Hom}}$ & $\begin{array}{l}\text { Amount of microsomal protein in the homogenate, based on } \\
\text { starting tissue weight and the MPPGK. }\end{array}$ & $\mathrm{mg}$ \\
\hline Mic_GST Hom & $\begin{array}{l}\text { Activity of GST in the homogenate attributable to microsomal } \\
\text { isoform(s) }\end{array}$ & $\mathrm{nmol} / \mathrm{min}$ \\
\hline Yield $_{\mathrm{GST} \text {,theor,corrected }}$ & $\begin{array}{l}\text { Theoretical cytosolic GST activity yield. The GST activity yield } \\
\text { in the homogenate that was attributed to the cytosolic fraction } \\
\text { (i.e., corrected for the microsomal GST activity) }\end{array}$ & $\mathrm{nmol} / \mathrm{min}$ \\
\hline S9_contribution $\mathrm{Hom}$ & $\begin{array}{l}\text { Theoretical \% contribution of the microsomal protein and } \\
\text { cytosolic protein (i.e., S } 9 \text { fraction) to overall protein in } \\
\text { homogenate }\end{array}$ & $\%$ \\
\hline
\end{tabular}

\section{Mycophenolic Acid Glucuronidation Depletion Assay in Human Kidney Microsomes}

Mycophenolic acid was selected as a clinically relevant marker to assess the metabolic activity of the prepared human kidney cortex microsomes, and investigate the variability of UGT activity within the kidney cortex samples. Mycophenolic acid has previously been shown to undergo glucuronidation in vitro in human liver, intestine, and kidney microsomes (Picard et al., 2005; Cubitt et al., 2009; Gill et al., 2012), with UGT1A9 identified as the major enzyme involved in its renal metabolism and UGT2B7 having a lesser role (Picard et al., 2005). Microsomal glucuronidation substrate depletion intrinsic clearance assays were performed for a subset of 20 donors (CMFT) using a method previously reported (Gill et al., 2012), including a no-cofactor control. The mycophenolic acid reactions were performed at a substrate concentration of $1 \mu \mathrm{M}$, which was expected to be under linear conditions considering the reported $K_{\mathrm{m}}$ values for UGT1A9 and UGT2B7 (Bernard and Guillemette, 2004; Picard et al., 2005). Because of low availability of microsomal protein, only one replicate for each donor was performed; each assay was done in triplicate. The assay was also performed in XenoTech pooled human kidney microsomes (13 donors, mixed gender). Human kidney microsomes $(0.25 \mathrm{mg} / \mathrm{ml})$ were activated by preincubation with $50 \mu \mathrm{g} / \mathrm{mg}$ protein alamethicin in assay buffer for $15 \mathrm{~min}$ on ice. Mycophenolic acid was preincubated with alamethicin-activated microsomes and bovine serum albumin (BSA; assay concentration 1\%) for $5 \mathrm{~min}$ in assay buffer at $37^{\circ} \mathrm{C}$ shaking at $900 \mathrm{rpm}$ (Eppendorf thermomixer; Hamburg, Germany)). Reaction was initiated by the addition of uridine-diphosphate-glucuronic acid at a final assay concentration of $5 \mathrm{mM}$. After incubation at $37^{\circ} \mathrm{C}$ with shaking at $900 \mathrm{rpm}$, aliquots of the incubation mixture were quenched in two volumes of icecold acetonitrile containing $1 \mu \mathrm{M}$ warfarin (internal standard) at eight time points between 0 and $60 \mathrm{~min}$ inclusive. Minimal depletion of mycophenolic acid was observed after $60 \mathrm{~min}$ at $0.25 \mathrm{mg} / \mathrm{ml}$ for donor CMFT1; therefore, a modified assay, with a protein concentration of $0.5 \mathrm{mg} / \mathrm{ml}$ and time points extended to $90 \mathrm{~min}$, was used for this donor. Quenched samples were stored at $-20^{\circ} \mathrm{C}$ for at least $1 \mathrm{~h}$ and then centrifuged at $9000 \mathrm{rpm}$ for $20 \mathrm{~min}$. Aliquots of supernatant were analyzed by liquid chromatography-mass spectrometry (LC-MS/MS) for mycophenolic acid concentration using matrix-matched calibration standards $(0-5 \mu \mathrm{M})$. To preserve individual donor human kidney cortex microsome samples, XenoTech pooled human kidney microsomes were used for preparing calibration standards.
LC-MS/MS analysis was performed using an Agilent 1100 HPLC system (Stockport, Cheshire, UK) coupled to a Micromass Quattro Ultima triple quadruple mass spectrometer (Waters, Elstree, Hertfordshire, UK). LC was performed using a Luna C18 $(3 \mu, 50 \times 4.6 \mathrm{~mm})$ column (Phenomenex, Torrance, CA) with appropriate elution gradient (Supplemental Table S1) and a flow rate of $1 \mathrm{ml} / \mathrm{min}$. The retention times of mycophenolic acid and warfarin were 4.21 and $4.49 \mathrm{~min}$, respectively. For MS, source temperature, desolvation temperature, desolvation gas flow rate, cone gas flow rate, and capillary voltage were $125^{\circ} \mathrm{C}$, $350^{\circ} \mathrm{C}, 600 \mathrm{l} / \mathrm{h}, 50 \mathrm{l} / \mathrm{h}$, and $3.5 \mathrm{kV}$, respectively. Selective reaction monitoring of mycophenolic acid and warfarin with negative electrospray ionization was performed; transitions of precursor to product ions $(\mathrm{m} / \mathrm{z})$ were $318.90 \rightarrow 191.10$ for mycophenolic acid and $306.90 \rightarrow 161.05$ for warfarin. Cone voltage and collision voltage were $90 \mathrm{~V}$ and $25 \mathrm{eV}$ for mycophenolic acid and $130 \mathrm{~V}$ and $19 \mathrm{eV}$ for warfarin, respectively.

\section{Genotyping of Selected Polymorphisms in UGT1A8, 1A9, and 2B7}

Genotyping of 20 human kidney cortex samples for selected single-nucleotide polymorphisms (SNPs) genes encoding the UGT1A8 (rs17863762), UGT1A9 (rs17868320, rs2741045, rs6714486, rs72551330, rs2741046), and UGT2B7 (rs7438135) enzymes was performed by NewGene (Newcastle upon Tyne, UK). These SNPs were selected on the basis of clinical data indicating that they are associated with interindividual variability in pharmacokinetic and pharmacodynamic endpoints of mycophenolic acid (Picard et al., 2005; Prausa et al., 2009; Fukuda et al., 2012). Briefly, after DNA extraction from tissue using a Promega Maxwell automation platform, polymerase chain reaction, and extension reaction, analysis was performed on the Agena MassARRAY4 platform. Each sample was run in duplicate.

\section{Prediction of In Vivo Mycophenolic Acid Glucuronidation Clearance}

Human kidney cortex microsomal intrinsic clearance $\left(\mathrm{CL}_{\text {int,UGT,HKM}}\right.$; $\mu 1 / \mathrm{min} / \mathrm{mg}$ of microsomal protein) for mycophenolic acid was calculated from the elimination rate constant $\left(k ; \mathrm{min}^{-1}\right)$ and the microsomal protein concentration of the incubation $(\mathrm{mg} / \mathrm{ml})$ using eq. $13 ; k$ was calculated from the slope of the linear correlation of the natural log-fraction remaining (average of triplicate incubations at each time point) versus time. In vitro $\mathrm{CL}_{\text {int,UGT,HKM }}$ data for each donor were corrected for the fraction unbound in the incubation 
$\left(f_{\mathrm{u}, \text { inc }} ; 0.18\right.$ at all microsomal protein concentrations, obtained in the presence of $1 \%$ BSA, as previously reported) (Gill et al., 2012) to calculate the unbound intrinsic clearance $\left(\mathrm{CL}_{\mathrm{int}, \mathrm{u}, \mathrm{UGT}, \mathrm{HKM}}\right)$. The $\mathrm{CL}_{\mathrm{int}, \mathrm{u}, \mathrm{UGT}, \mathrm{HKM}}$ data were scaled using MPPGK and average kidney weight of $4.5 \mathrm{~g} / \mathrm{kg}$ of body weight. Prediction of in vivo mycophenolic acid renal glucuronidation clearance $\left(\mathrm{CL}_{\mathrm{R}, \mathrm{met}, \mathrm{UGT}}\right)$ was done using the well stirred kidney model (eq. 14), fraction unbound in plasma $\left(f_{\mathrm{u}, \mathrm{p}}\right)$ and blood-to-plasma concentration ratio $\left(R_{\mathrm{B}}\right)$ of 0.01 and 0.6 , respectively (Gill et al., 2012).

The IVIVE of mycophenolic acid $\mathrm{CL}_{\mathrm{R} \text {,met,UGT }}$ was performed using two different scenarios for scaling factors, as summarized in Table 2. An MPPGK of $11.1 \mathrm{mg} / \mathrm{g}$ kidney was applied in Scenario 1; this value was calculated as the weighted (by donor number) mean of literature values reported by studies that used mixed kidney (i.e., cortex and medulla) or unspecified region (Al-Jahdari et al., 2006; Knights et al., 2016). In Scenario 2, the $\mathrm{CL}_{\text {int,u,UGT,HKM }}$ values for each donor were scaled by the corresponding MPPGK value obtained for kidney cortex in the current study. Prediction of in vivo metabolic clearance also requires information on organ weight and blood flow; for Scenario 1, whole kidney weight and renal blood flow $\left(Q_{\mathrm{R}}\right)$ were used, whereas cortex weight and cortical blood flow were used in Scenario $2(68 \%$ and $80 \%$ of the respective values for the whole kidney (Lerman et al., 1996; Vallée et al., 2000) (Table 2).

Predicted overall mycophenolic acid glucuronidation clearance rates were calculated as the sum of the renal (eq. 14) and hepatic $\left(\mathrm{CL}_{\mathrm{h}, \text { met,UGT }}\right)$ glucuronidation clearances (eq. 15). Analogous to renal metabolism, $\mathrm{CL}_{\mathrm{h} \text {,met, }}$ UGT was calculated with the well stirred liver model, using scaled $\mathrm{CL}_{\text {int,u,UGT,HLM }}$ of $9.32 \mathrm{ml} / \mathrm{min} / \mathrm{g}$ liver, obtained under the same BSA conditions in vitro, as reported in Gill et al. (2012). MPPGL of $40 \mathrm{mg} / \mathrm{g}$ of liver, liver weight of $21.4 \mathrm{~g} / \mathrm{kg}$ of body weight, and hepatic blood flow $\left(\mathrm{Q}_{\mathrm{h}}\right)$ of $20.7 \mathrm{ml} / \mathrm{min} / \mathrm{kg}$ were used, as previously reported (Gill et al., 2012). Observed mycophenolic acid glucuronidation clearance $\left(\mathrm{CL}_{\mathrm{UGT}}\right)$ of $3.97 \mathrm{ml} / \mathrm{min} / \mathrm{kg}$ (Gill et al., 2012) was used to assess the predictive performance of the IVIVE. This value is based on a plasma i.v. clearance of $2.49 \mathrm{ml} / \mathrm{min} / \mathrm{kg}$ corrected for the renal excretion $(0.01 \mathrm{ml} / \mathrm{min} / \mathrm{kg})$ and the fraction metabolized by UGT ( $\mathrm{f}_{\mathrm{m}, \mathrm{UGT}}$ of 0.95 , obtained from urinary excretion data):

$$
\begin{gathered}
C L_{\text {int }, U G T, H K M}=\frac{k \times V}{\text { amount of microsomal proteinin in cubation }} \\
C L_{R, \text { met }, U G T}=\frac{Q_{R} \times f_{u, p} / R_{B} \times C L_{\text {int }, u, U G T, H K M}}{Q_{R}+f_{u, p} / R_{B} \times C L_{\text {int }, u, U G T, H K M}} \\
C L_{U G T}=C L_{h, \text { met }, U G T}+C L_{R, \text { met }, U G T}
\end{gathered}
$$

\section{Data Analysis}

CYP content and microsomal protein per gram of intestine (MPPGI) data for 14 dog intestinal samples were provided by Dr Oliver Hatley (manuscript in preparation). These data were obtained from different regions of the intestine, with each region being defined as one sixth of the entire intestine by length. The initial three regions were defined as proximal 1,2 , and 3 ; the final region was defined as distal.

Average (mean) values were calculated, with variability estimated using the coefficient of variation $(\mathrm{CV} ; \%)$. Interassay variability $(\%)$ was estimated as the average between-assay $\mathrm{CV}$ for each set of samples. Data were analyzed using MS Excel. Student's $t$ test (paired, two-tailed) was used to statistically compare means; $P<0.05$ was considered significant. The unpaired $t$ test was used for comparison of CYP content in homogenates prepared from fresh and frozen kidney cortex owing to differences in the number of samples in each group.
Results

\section{Characterization and Optimization of Protein Marker Assays}

In the initial phase of the study, the validity of three different markers was investigated, together with assessment of assay reproducibility.

CYP Content Assay. Compared with the liver, $450 \mathrm{~nm}$ absorbance signal in the sodium dithionite difference spectra was generally weak in kidney cortex but sufficient for quantification. On average, the interassay variability of CYP content was $10 \%$ and $5 \%$ for homogenate and microsomes, respectively, and $14 \%$ for the calculated microsomal protein enrichment factor. Based on data from one dog, for which two separate batches of microsomes were prepared, the interassay variability in CYP content measurement was similar to the apparent interbatch variability (Supplemental Fig. S4). This trend was also noted for the calculated CYP content enrichment factor (approx. 12\% variability for interbatch and interassay).

G6Pase Activity Assay. Dog kidney cortex G6Pase activity appeared to be linear with respect to protein concentration in both homogenate and microsomes, but it was not directly proportional (i.e., intercept $\neq 0$ ) (Supplemental Fig. S5). Activity could not be reliably quantified at the lower protein concentrations $(\leq 0.1 \mathrm{mg} / \mathrm{ml})$ for homogenate. The resultant microsomal protein recovery factors calculated for each assay protein concentration did not appear to show protein dependency. Therefore, G6Pase activity was considered a suitable marker to estimate microsomal protein losses. The average interassay variability (CV) of G6Pase activity was $20.6 \%$ and $19.8 \%$ for homogenate and microsomes, respectively, whereas G6Pase activity enrichment factor interassay variability was $14 \%$.

In human kidney cortex, the interassay variability of G6Pase assay appeared to be greater than the interbatch variability (Supplemental Fig. S6). The average interassay variability in G6Pase activity was $15 \%$ and $19 \%$ for homogenate and microsomes, respectively, which resulted in an average interassay variability of $18 \%$ for the calculated G6Pase activity enrichment factor (range, 3\%-39\%).

GST Activity Assay. GST activity was nonlinear with respect to protein concentration in both rat kidney homogenate and cytosol (Supplemental Fig. S7). GST activity could be reliably quantified at the lower protein concentrations $(\leq 5 \mu \mathrm{g} / \mathrm{ml})$, albeit with lower reproducibility in homogenate. There was low interassay variability at the protein concentration selected for the final assay $(10 \mu \mathrm{g} / \mathrm{ml})$. Assay protein concentration did not appear to affect the apparent enrichment factor (Supplemental Fig. S7). Therefore, GST activity was considered a suitable marker for cytosolic protein.

\section{Estimation of Microsomal Protein Content in Dog Kidney Cortex and Liver and Comparison with Intestine}

Liver and kidney cortex samples were obtained from a total of 17 dogs. Average CYP content in dog kidney cortex homogenate prepared from frozen kidney tissue was $0.056 \mathrm{nmol} / \mathrm{mg}$ protein $(n=17)$, which was significantly lower $(P<0.05)$ than that in homogenate prepared from fresh kidney cortex tissue $(0.086 \mathrm{nmol} / \mathrm{mg}$ protein;

TABLE 2

Physiologic values used for $\mathrm{CL}_{\mathrm{R}, \text { met,UGT }}$ predictions using IVIVE in different scenarios

\begin{tabular}{lcc}
\hline \multicolumn{1}{c}{ Parameter $(\mathrm{U})$} & Scenario 1 (Whole Kidney) & Scenario 2 (Kidney Cortex) \\
\hline MPPGK (mg/g kidney) & $11.1^{a}$ & Donor specific $^{b}$ \\
Kidney weight (g/kg body weight) & 4.5 & 3.1 \\
Renal blood flow (ml/min/kg body weight) & 16.4 & 13.2 \\
\hline
\end{tabular}

${ }^{a}$ Weighted (by number of donors) mean of values reported for microsomes prepared from mixed kidney or unspecified region (Al-Jahdari et al., 2006; Knights et al., 2016).

${ }^{b}$ Fig. 5 and (Supplemental Table S3). 
$n=14$ ) (Table 3). Both CYP content and G6Pase activity were statistically significantly lower $(P<0.05)$ in dog kidney cortex compared with corresponding livers (data were available only for frozen tissue samples). Mean CYP content for dog kidney cortex microsomes was more than 3-fold greater than for intestinal microsomes (samples were available from fresh tissue only). No trends were apparent in the CYP content or G6Pase activity between the liver and kidney cortex, based on visual assessment of the data.

Mean MPPGK in dog kidney cortex was $43.1 \mathrm{mg} / \mathrm{g}$ kidney cortex when CYP content was used as microsomal protein marker and samples were prepared from fresh kidney cortex (Table 3); individual values ranged from 27.4 to $58.6 \mathrm{mg} / \mathrm{g}$ kidney cortex (Supplemental Table S2). This was on average $27 \%$ higher than the corresponding value when samples were prepared from frozen kidney cortex. MPPGK was on average $18 \%$ or $31 \%$ lower than MPPGL when CYP content or G6Pase activity was used as microsomal protein marker, respectively (Table 3). This difference varied between dogs, but no apparent correlation was found in MPPGK and MPPGL (Fig. 2). Both MPPGL and MPPGK were consistently greater than MPPGI for all regions of intestine studied, with no trends apparent, either when considering data for each region separately or data for all intestinal regions collectively. No clear trends between either MPPGL or MPPGK and factors such as age or dog weight were apparent (data not shown). Dog microsomal protein content was lower when using CYP content than when using G6Pase activity as microsomal marker, by 23\% for MPPGK and 35\% for MPPGL (Table 3). Bland-Altman plots show that the $95 \%$ confidence intervals for the mean difference between the markers do not overlap with the line of unity (difference $=0$ ), suggesting systematic bias (Fig. 3).

\section{Estimation of MPPGK and CPPGK in Human Kidney Cortex}

Average G6Pase activities of human kidney cortex homogenate and microsomes were 8.1 and $27.9 \mathrm{nmol} / \mathrm{min} / \mathrm{mg}$ protein $(n=38$ kidney cortex samples), with CVs of $61 \%$ and $53 \%$, respectively (Fig. 4A). The G6Pase activities were higher in samples obtained from Newcastle University $(9.2$ and $31.1 \mathrm{nmol} / \mathrm{min} / \mathrm{mg}$ protein in homogenate and microsomes, respectively; $n=18$ ) compared with those obtained from the CMFT Biobank (7.1 and $24.9 \mathrm{nmol} / \mathrm{min} / \mathrm{mg}$ protein in homogenate and microsomes, respectively; $n=20$ ). Average GST activities of human kidney cortex homogenate, microsomes, and cytosol were 217, 106, and $318 \mathrm{nmol} / \mathrm{min} / \mathrm{mg}$ protein, respectively $(n=38)$; CVs for those samples were between $40 \%$ and $44 \%$ (Fig. 4B). Analogous to G6Pase, GST activities were higher in samples obtained from Newcastle University (234, 112, and $357 \mathrm{nmol} / \mathrm{min} / \mathrm{mg}$ protein in homogenate, microsomes, and cytosol; $n=18$ ) compared with those obtained from CMFT Biobank (202, 100, and $284 \mathrm{nmol} / \mathrm{min} / \mathrm{mg}$ protein in homogenate, microsomes, and cytosol, respectively; $n=20$ ).

Average MPPGK in humans obtained from all 38 samples was $26.2 \mathrm{mg}$ of protein/g kidney cortex, with a CV of $27 \%$ (Fig. 5 and
Table 4). Microsomal GST activity, scaled using MPPGK to units of $\mathrm{nmol} / \mathrm{min} / \mathrm{g}$ kidney cortex, represented on average $14.5 \%$ of the GST activity yield in human kidney cortex homogenate. After correction for activity attributable to microsomal GST isoform(s) in the homogenate, average human CPPGK was $53.3 \mathrm{mg}$ protein/g kidney cortex, with $31 \%$ CV (Fig. 5 and Table 4). There was no apparent trend between MPPGK and CPPGK (Supplemental Fig. S8). The average S9 protein per gram of kidney cortex (i.e., the sum of MPPGK and CPPGK) was $79.5 \mathrm{mg}$ protein/g kidney cortex $(n=38)$. Theoretical contribution of the $\mathrm{S} 9$ protein to the protein content of homogenate was $89 \%$ on average, although the value exceeded $100 \%$ for seven of 38 samples (Fig. 5). Based on the subset of 20 donors for whom demographic data were available, no trends between human MPPGK or CPPGK and factors, such as age, gender, and weight, were found (not shown). MPPGK and CPPGK of samples from CMFT Biobank were each significantly greater than the values obtained from samples from Newcastle University $(P<$ 0.05; two-tailed $t$ test). Observed MPPGK variability for CMFT Biobank samples was one third lower than Newcastle University samples (Table 4).

\section{In Vitro Glucuronidation of Mycophenolic Acid by Human Kidney Cortex Microsomes and IVIVE}

Mycophenolic acid $\mathrm{CL}_{\text {int,u,UGT,HKM }}$ was measured in $20 \mathrm{CMFT}$ Biobank individual human kidney cortex microsomes and XenoTech pooled kidney microsomes (Supplemental Fig. S9). Average $\mathrm{CL}_{\text {int,u,UGT,HKM }}$ in the 20 donors was $1061 \mu \mathrm{l} / \mathrm{min} / \mathrm{mg}$ microsomal protein, with $43 \% \mathrm{CV}$ and range of $93-1896 \mu \mathrm{l} / \mathrm{min} / \mathrm{mg}$ microsomal protein for donor CMFT1 and CMFT5, respectively. The average value was approximately 2-fold lower compared with mycophenolic acid $\mathrm{CL}_{\text {int,u,UGT,HKM }}$ obtained in the commercially sourced pooled kidney microsomes in the current study (1843 $\mu \mathrm{l} / \mathrm{min} / \mathrm{mg}$ protein). No depletion of mycophenolic acid was observed in the no-cofactor control for any of the donors investigated. A positive correlation between mycophenolic acid $\mathrm{CL}_{\text {int,u,UGT,HKM }}$ and G6Pase activity was noted (Supplemental Fig. S10). A weak trend between mycophenolic acid $\mathrm{CL}_{\text {int,u,UGT,HKM and UGT2B7 }}$ genotype -900G > A (rs7438135) was noted (AA > GA > GG (Fig. 6); the low number of donors relative to the number of polymorphisms tested precluded statistical assessment of this trend. This trend was reflected in the predicted $\mathrm{CL}_{\mathrm{UGT}}$, as six of seven of the donors with predicted/observed $\mathrm{CL}_{\mathrm{UGT}}<1.0$ (Scenario 2) had the GG or GA genotype. No other trends between genotype and mycophenolic acid $\mathrm{CL}_{\text {int,u,UGT,HKM }}$ were apparent for the polymorphisms investigated (Supplemental Table S3).

Scaled mycophenolic acid $\mathrm{CL}_{\text {int,u,UGT,HKM }}$ (per gram of organ weight) was on average 2.6-fold greater when the donor-specific MPPGK values measured using cortex tissue in the current study were applied (i.e., Scenario 2) than when the MPPGK value calculated for whole kidney was used (i.e., Scenario 1) (Table 5). These differences were reflected

TABLE 3

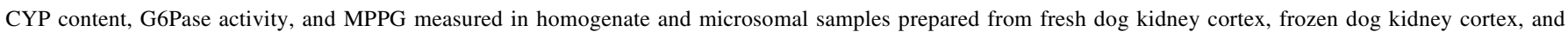
frozen dog liver

Average values are presented, with CVs in parentheses. G6Pase activity was not measured in samples prepared from fresh dog kidney cortex. Data for individual dogs are presented (Supplemental Table S2).

\begin{tabular}{|c|c|c|c|c|c|c|c|}
\hline & & \multicolumn{2}{|c|}{ CYP Content (nmol/mg Protein) } & \multicolumn{2}{|c|}{ G6Pase Activity (nmol/min/mg Protein) } & \multicolumn{2}{|c|}{ MPPG (mg/g Tissue) } \\
\hline & & Homogenate & Microsomes & Homogenate & Microsomes & CYP content & G6Pase activity \\
\hline \multirow[t]{2}{*}{ Fresh tissue $(n=14)$} & Dog kidney cortex & $0.086(24 \%)$ & $0.205(23 \%)$ & Not measured & Not measured & $43.1(22 \%)$ & Not measured \\
\hline & Dog intestine $^{a}$ & Data not available & $0.059(27 \%)$ & Not measured & Not measured & $6.5(61 \%)$ & Not measured \\
\hline \multirow[t]{2}{*}{ Frozen tissue $(n=17)$} & Dog kidney cortex & $0.056(16 \%)$ & $0.230(15 \%)$ & $19.9(16 \%)$ & $62.1(16 \%)$ & $33.9(18 \%)$ & $44.0(16 \%)$ \\
\hline & Dog liver & $0.113(19 \%)$ & $0.665(20 \%)$ & $23.8(15 \%)$ & $91.2(18 \%)$ & $41.1(12 \%)$ & $63.6(18 \%)$ \\
\hline
\end{tabular}

${ }^{a}$ Data for dog intestine were provided by Dr Oliver Hatley (manuscript in preparation) and represent data pooled from several intestinal regions. 


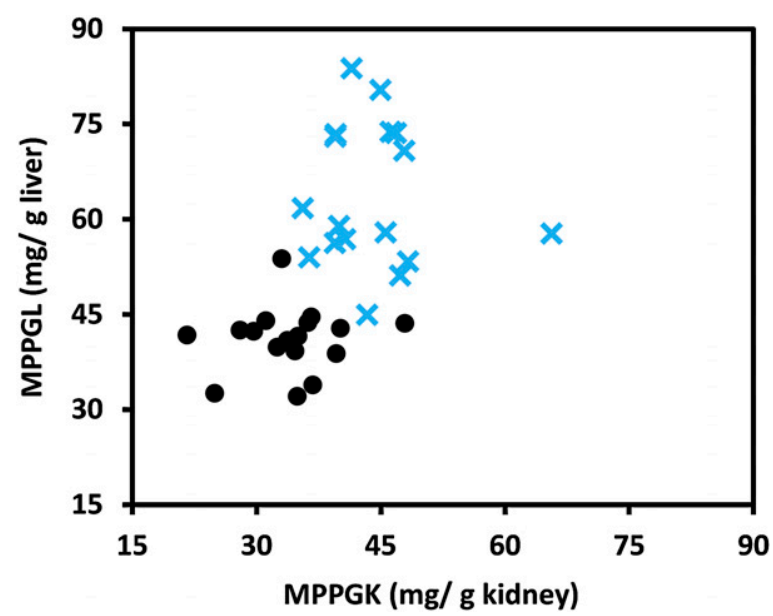

Fig. 2. Comparison of MPPGK and MPPGL in $\operatorname{dogs}(n=17 \mathrm{dogs})$ using either CYP content (black circle) or G6Pase activity (blue cross) as the microsomal protein marker. Each point represents microsomal scalar measured using a single batch of homogenates and microsomes from a single dog.

in the assessment of the importance of renal glucuronidation relative to liver, i.e., the kidney:liver ratios for $\mathrm{CL}_{\mathrm{int}, \mathrm{u}, \mathrm{UGT}}$ (calculated using published data for liver, obtained using comparable in vitro assay conditions to the current study, i.e., 1\% BSA) (Gill et al., 2012) (Fig. 7A).

Underprediction of mycophenolic acid $\mathrm{CL}_{\mathrm{UGT}}$ was observed when only the hepatic contribution to glucuronidation clearance was considered (Fig. 7B). Accounting for both the hepatic and renal contributions improved the prediction of $\mathrm{CL}_{\mathrm{UGT}}$ for both Scenario 1 and 2. Whereas for Scenario 1, uniformity in glucuronidation activity throughout kidney is assumed (common assumption in the literature (Gill et al., 2012; Knights et al., 2016), Scenario 2 has the assumption that glucuronidation occurs only in cortex (by applying cortex tissue weight and blood flow in the well stirred kidney model). Predicted $\mathrm{CL}_{\mathrm{UGT}}$ was approximately $15 \%$ greater in Scenario 2 compared with Scenario 1 (Table 5), as demonstrated in the respective predicted/observed ratios (Scenario 1: 0.93; Scenario 2: 1.06) (Fig. 7B). Application of the cortical MPPGK obtained in the current study for the whole kidney (in conjunction with kidney weight and blood flow) would increase the predicted $\mathrm{CL}_{\mathrm{R}, \mathrm{met}, \mathrm{UGT}}$ by $43 \%$ compared with that of Scenario 2 .

\section{Discussion}

Microsomal and cytosolic protein contents in tissues of human and preclinical species are used as scaling factors for IVIVE of microsomal metabolism data to predict drug in vivo clearance. Information on the microsomal scalar in human kidney is limited compared with the liver (Scotcher et al., 2016b). Data on the cytosolic protein in human kidney and the microsomal and cytosolic protein in preclinical species (that have explicitly accounted for protein recovery) are lacking.

In the current study, the microsomal protein content of dog kidney cortex was measured using two different microsomal protein recovery markers and compared with the corresponding values in matched liver and intestine. Further, the microsomal and cytosolic protein content was measured in 38 human kidney cortex samples. For 20 of these samples, the functional activity was assessed using a mycophenolic glucuronidation substrate depletion assay. These data were used to assess the impact of different MPPGK values, as well as different assumptions concerning the contribution of whole kidney versus only the cortex to renal drug glucuronidation, on prediction of in vivo mycophenolic acid glucuronidation clearance.
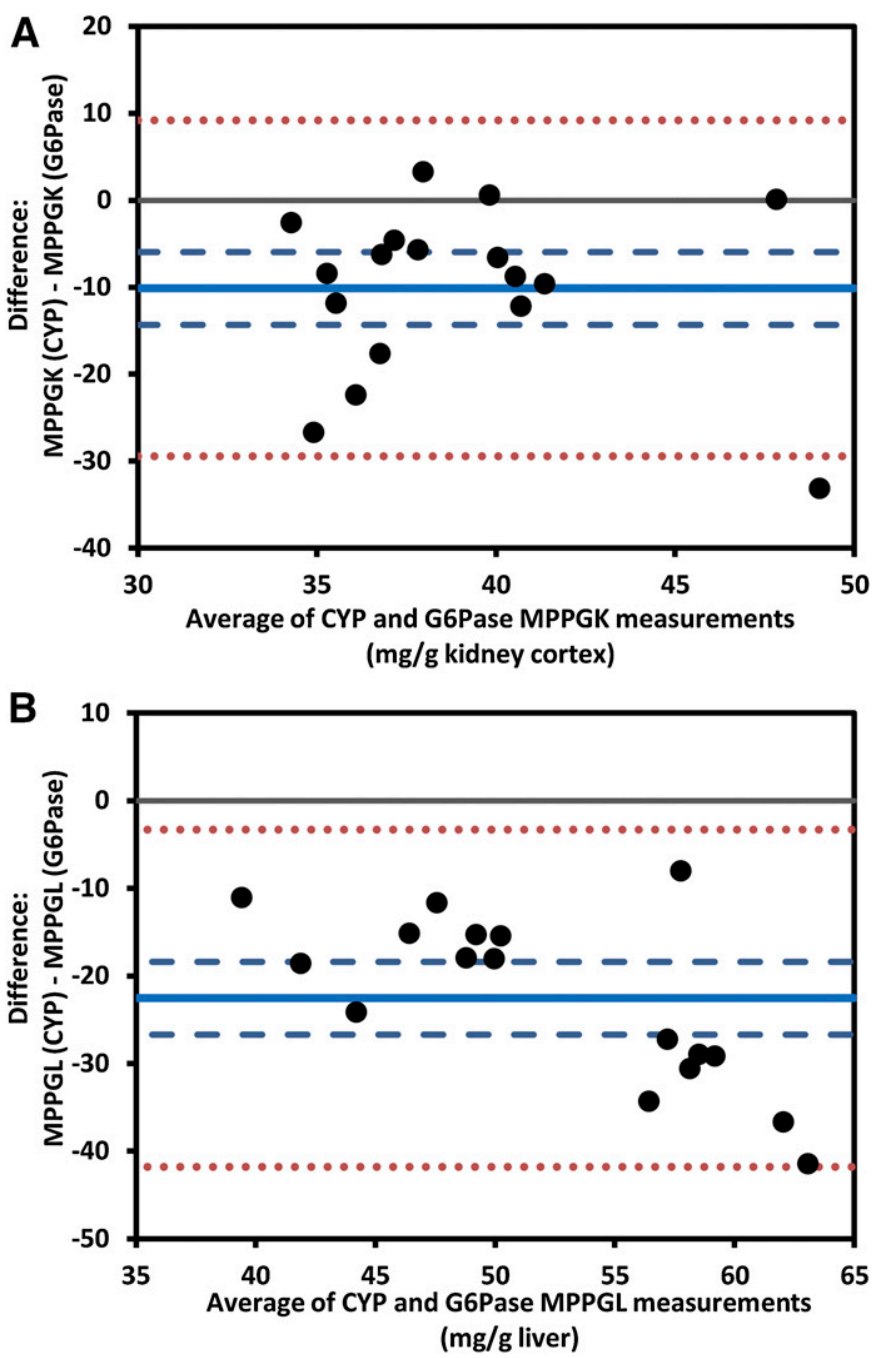

Fig. 3. Bland-Altman plots: difference in MPPG measured using CYP content versus G6Pase activity as microsomal protein marker. Points on graphs represent measurements made in kidney cortex (A) or liver (B) microsome and homogenate samples. Blue lines represent mean (solid) and $95 \%$ confidence interval of mean (dashed) difference between MPPGs. Red dotted lines represent $95 \%$ limits of agreement. Thin black lines represent line of unity.

\section{Suitability of Microsomal and Cytosol Protein Markers for Correction of Protein Losses}

Ensuring complete homogenization of kidney tissue, while also limiting contamination of microsomes with other sources of haemoproteins such as mitochondria, can be challenging. When measuring CYP content in kidney cortex, the low CYP levels and potential for spectral interference from contaminating haemoproteins make accurate quantification challenging (Jakobsson and Cintig, 1973; Ohno et al., 1982). Preliminary experiments showed minor spectral interference in the dithionite difference spectra, and therefore bias in the CYP content measurements and subsequent MPPGK estimates was unlikely when considered alongside the interassay variability (Matsubara et al., 1976). Furthermore, the dog kidney cortex microsomal CYP content measured in the current study using the dithionite difference method (Table 3 ) was comparable to a value reported using a customized spectral method $(0.223 \mathrm{nmol} / \mathrm{mg}$ protein) (Ohno et al., 1982). CYP content measured in dog liver was also in good agreement with previously published values (Smith et al., 2008). Therefore, the standard dithionite difference spectra approach was deemed appropriate to be used in the current study. 

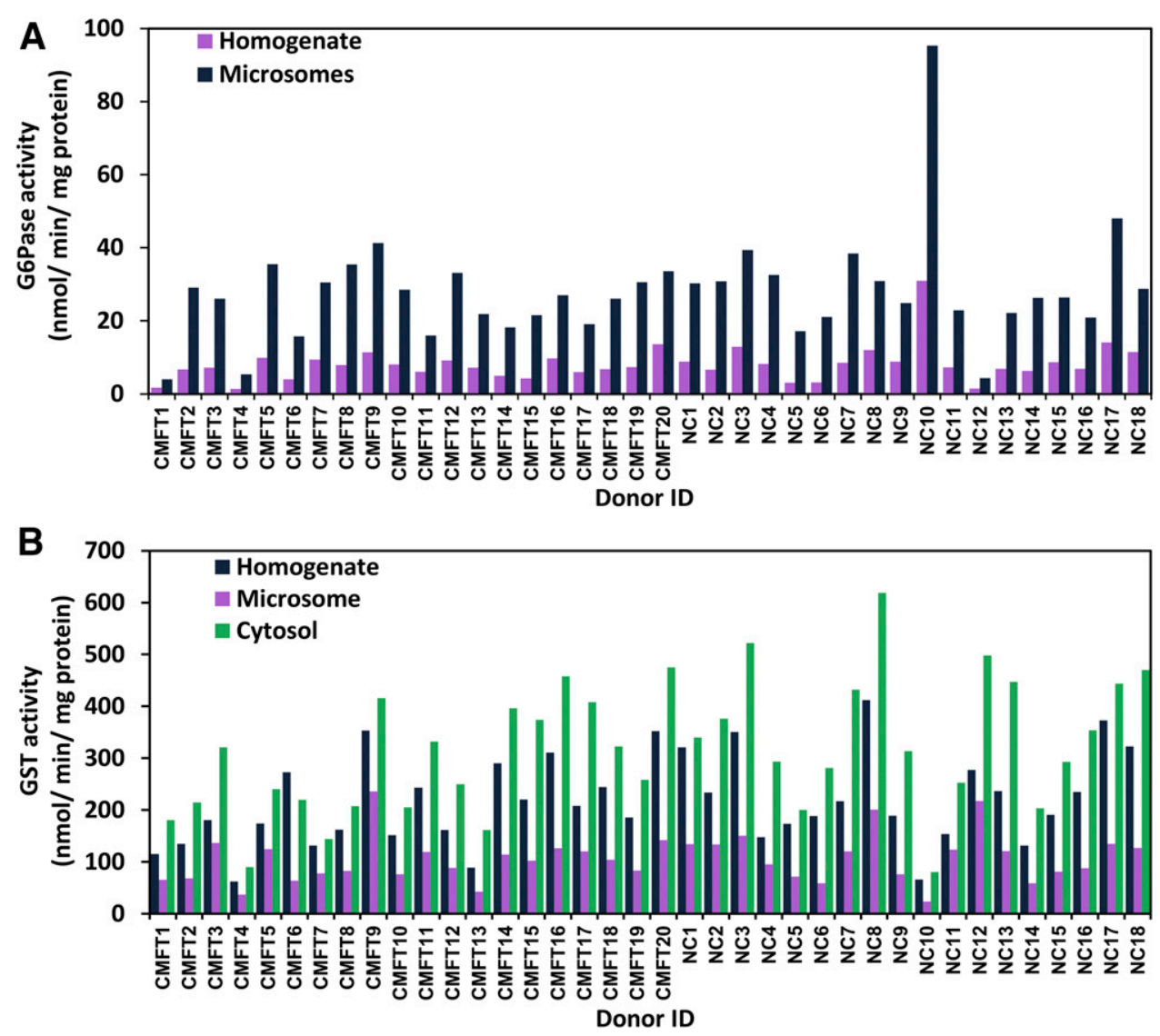

Fig. 4. Marker activities measured in 38 human kidney cortex samples. (A) G6Pase activity in homogenate and microsomes. (B) GST activity homogenate, microsomes, and cytosols. CMFT number and NC number indicate samples acquired from the CMFT Biobank or Newcastle University, respectively. Each bar typically represent $n=1$ measurements per donor, although for some samples bars represent the average of $n=2$ measurements. Individual values are listed (Supplemental Table S3).
G6Pase activity was selected as a possible alternative microsomal protein marker for correction of protein losses during centrifugation. The estimated microsomal protein recoveries in dogs using this marker (frozen tissue) were lower relative to CYP content in both liver (38\% for G6Pase and 58\% for CYP content) and kidney cortex (40\% for G6Pase and $53 \%$ for CYP content). Subsequently, the microsomal protein

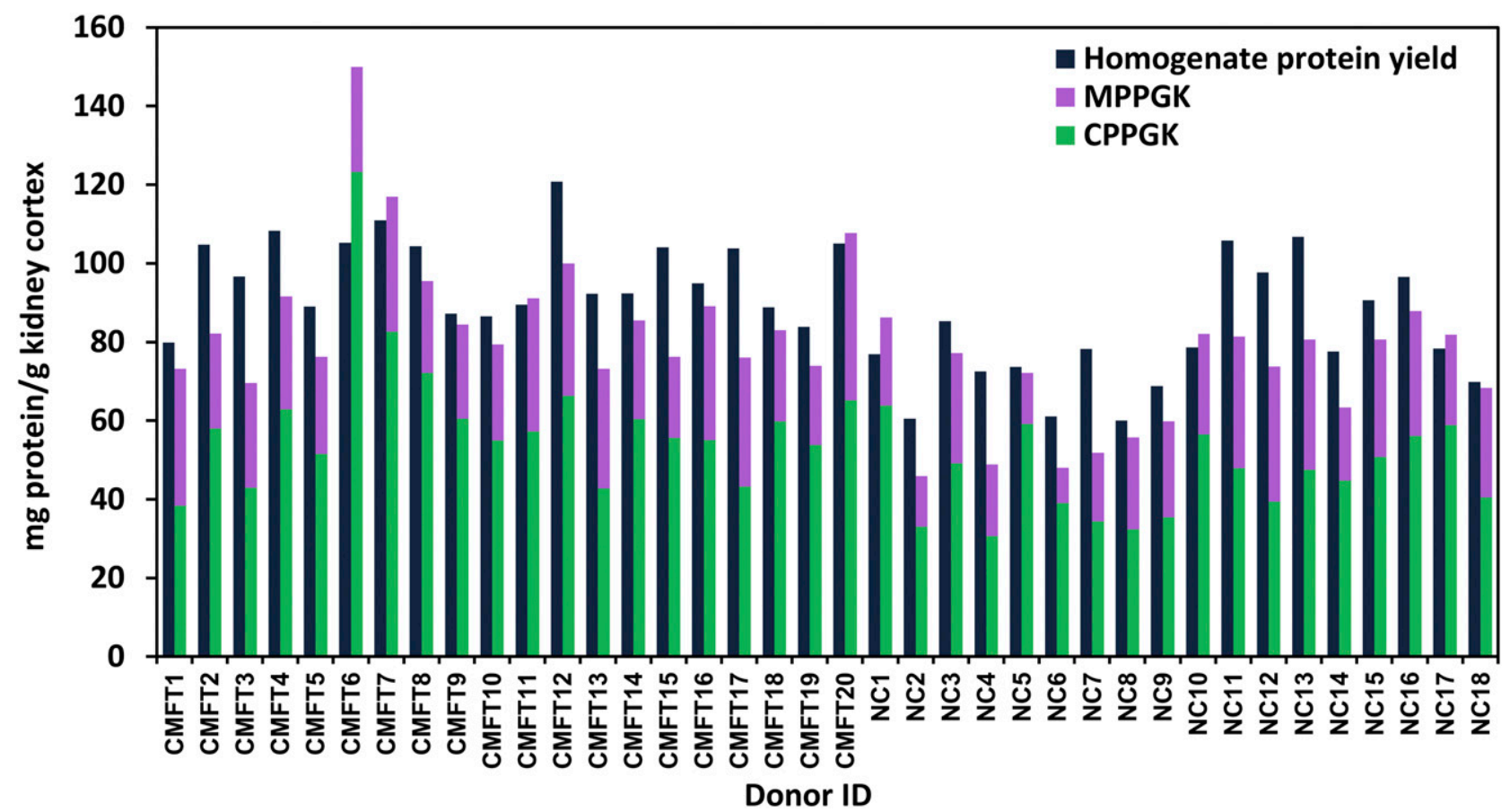

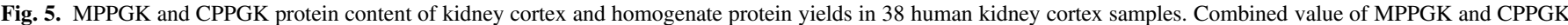

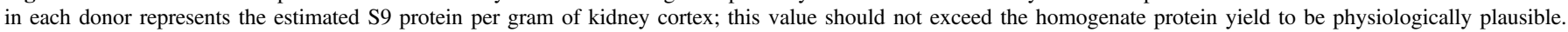

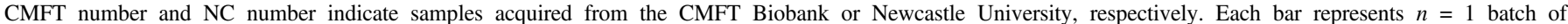
homogenate/microsomes/cytosol per donor. Individual values are listed (Supplemental Table S3). 
TABLE 4

MPPGK, CPPGK, and S9PPGK for samples prepared from frozen human kidney. Data for individual donors are presented (Supplemental Table S3)

\begin{tabular}{lccc}
\hline & MPPGK $(\mathrm{mg}$ Protein/g Kidney Cortex) & CPPGK (mg Protein/g kidney Cortex) & S9PPGK (mg Protein/g Kidney Cortex) \\
\hline All donors $(n=38)$ & & & 73.3 \\
$\quad$ Average & 26.2 & 31 & 24 \\
CV $(\%)$ & 27 & $30.6-123.2$ & $45.9-149.9$ \\
$\quad$ Range & $9.0-42.6$ & & 60.3 \\
CMFT donors only $(n=20)$ & 28.4 & 30 & 88.7 \\
$\quad$ Average & 21 & $38.4-123.2$ & 69 \\
CV $(\%)$ & $20.2-42.6$ & 45.5 & $69.6-149.9$ \\
Range & 23.7 & 23 & 69.2 \\
NC donors only $(n=18)$ & 32 & $30.6-63.8$ & 21 \\
$\quad$ Average & $9.0-34.3$ & & $45.9-87.8$ \\
CV $(\%)$ & & & \\
Range & & & \\
\hline
\end{tabular}

content estimates were higher when using G6Pase activity. Although G6Pase is present in the nuclear envelope, it is at very low levels relative to the endoplasmic reticulum and unlikely to fully explain the marker related differences in microsomal protein content (Kartenbeck et al., 1973; Nordlie, 1979). Despite the potential for overestimation of MPPG values using G6Pase, this marker was preferred for human samples over CYP content, because of the low sensitivity of the CYP content assay and expected higher biologic variability than in dogs.

A positive correlation between G6Pase activity and mycophenolic

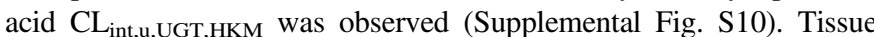
storage would be an unlikely cause, as CMFT kidney cortex samples were snap-frozen within $1 \mathrm{~h}$ of excision. Preliminary comparisons of G6Pase activity in different batches of human kidney cortex microsomes from the same donor showed good reproducibility (Supplemental Fig. S6), confirming that the homogenization procedure was consistent. Coregulation of G6Pase and UGT enzymes is a more likely explanation for the observed correlation between G6Pase activity and mycophenolic acid $\mathrm{CL}_{\text {int,u,UGT,HKM. Members of the hepatocyte nuclear factors }}$ families of transcription factors (HNF1 and HNF4) may be involved in regulating the expression of G6Pase (Lin et al., 1997; Rajas et al., 2002), UGT1A9 (Ramírez et al., 2008; Hu et al., 2014b), and UGT2B7 (Ramírez et al., 2008; Hu et al., 2014b). In addition, D-glucose and glucose-6-phosphate (substrate and product of G6Pase mediated reaction) and uridine-diphosphate-glucuronic acid (cofactor for UGTmediated glucuronidation) are closely positioned in the cellular metabolic pathway (http://biochemical-pathways.com/\#/map/1).

Both alcohol dehydrogenase and GST activity have been suggested as potential cytosolic protein markers (Cubitt et al., 2011). In the current study, implementation of the alcohol dehydrogenase activity assay was ineffective (data not shown). Therefore, GST activity was used as the human cytosolic protein marker, despite the presence of some GST also in the microsomes (Song et al., 2015). GST activity in human kidney cortex cytosol was higher than that in microsomes, in agreement with similar findings for human liver (Prabhu et al., 2004). Average GST activities in human kidney cortex microsomes were higher than a literature value by approximately one order of magnitude (Morgenstern et al., 1984); conversely, GST activities in human kidney cortex cytosols were on average lower than previously reported values for normal human kidney (Simic et al., 2001, 2003). Ignoring the proportion of GST activity in homogenate attributed to microsomal isoforms (14.5\%) when calculating the cytosolic protein recovery would result in an increase in the average estimated CPPGK by $13 \%$. In the extreme case, this $13 \%$ difference will contribute to potential systematic misprediction of in vivo metabolic clearance when using CPPGK as an IVIVE scaling factor for in vitro cytosolic metabolism data.

\section{Species and Tissue Differences in Subcellular Protein Content Estimates}

The direct comparison of microsomal content of liver and kidney cortex from samples obtained from the same animals showed no correlation between the scalars, although MPPGL was on average $45 \%$ higher than MPPGK (G6Pase as marker). The mean MPPGK value in $\operatorname{dog}(44.0 \mathrm{mg} / \mathrm{g}$ kidney cortex $)$ was higher than the corresponding value in human $(26.2 \mathrm{mg} / \mathrm{g}$ kidney cortex $)$, in agreement with literature data suggesting a similar relationship for MPPGL (Barter et al., 2007; Heikkinen et al., 2012, 2015). The variability observed in MPPGK in dogs was lower than that in humans, despite similar interassay variability in G6Pase activities, indicating greater biologic variability in human MPPGK. This trend is expected because of the higher genetic and environmental variability encountered in humans compared with that in laboratory animals.

The number of kidney cortex samples used to estimate human MPPGK in the current study $(n=38)$ was greater than the entire combined samples reported so far in the literature $(n=23$ across four studies) (Scotcher et al., 2016b) and therefore provides a more reliable indicator of true biologic variability in this microsomal scalar. Overall,

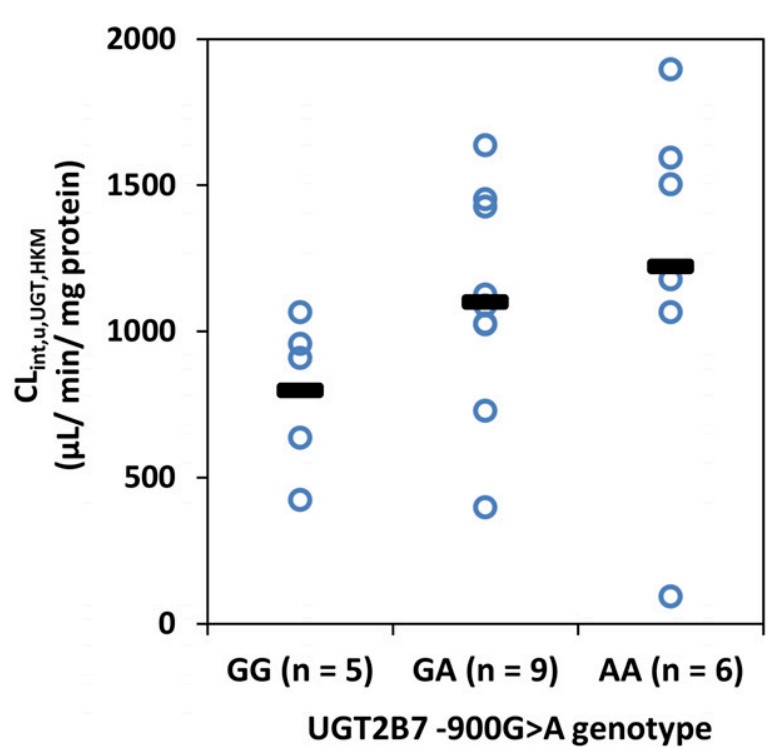

Fig. 6. Individual (blue open circle) and mean (black line) mycophenolic acid $\mathrm{CL}_{\text {int,u,UGT HKM }}(\mu \mathrm{l} / \mathrm{min} / \mathrm{mg}$ protein) for donors with different allelic variants for the $-900 \mathrm{G}>$ A SNP in the UGT2B7 gene (rs7438135). 
TABLE 5

Comparison of scaled mycophenolic acid $\mathrm{CL}_{\text {int,u,UGT,HKM }}$ and predicted $\mathrm{CL}_{\mathrm{UGT}}$ in scenarios that take different assumptions for physiologic parameters (see Table 2)

Mean values from 20 individual human kidney cortex microsomes are shown, with CVs in parentheses. Data for individual donors are listed (Supplemental Table S3).

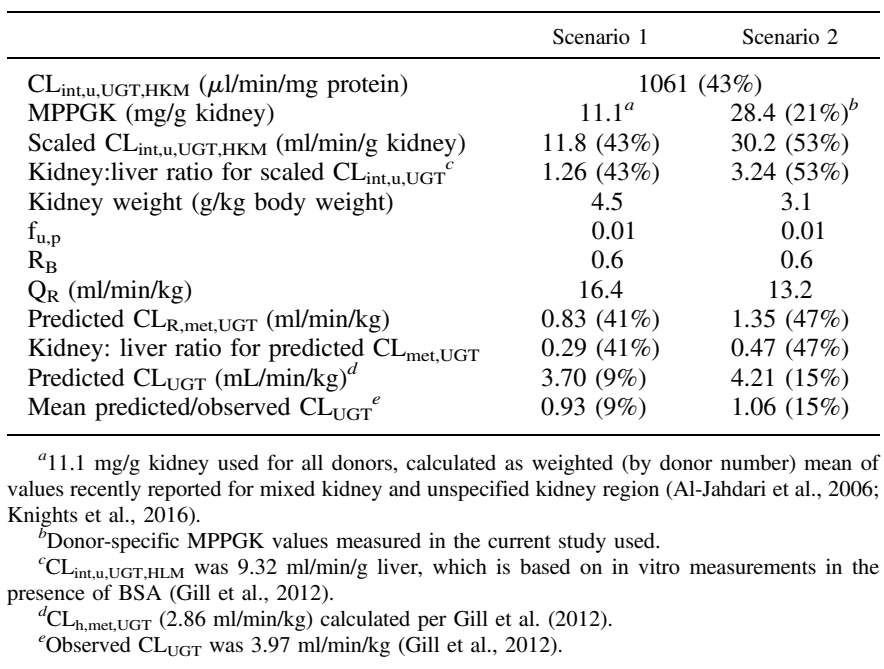

the mean MPPGK obtained here $(26.2 \mathrm{mg} / \mathrm{g}$ kidney cortex $)$ is in agreement with the value previously reported for kidney cortex microsomes (Jakobsson and Cintig, 1973), but it is more than 2-fold greater than recently reported scalars from unspecified regions or "mixed" kidney samples (Al-Jahdari et al., 2006; Knights et al., 2016). Although studies differed in microsomal protein markers used, the kidney region used is most likely the major contributor to the MPPGK differences because of higher endoplasmic reticulum content in cortex relative to medulla. This emphasizes a need for separate MPPGK scalars for cortex and whole kidney.

In addition to protein marker and kidney region, tissue source and processing were identified as important factors contributing to variability in scalars, as significant differences in MPPGK and CPPGK were found between the two sources of kidney cortex used in the current study. Demographic information, such as age, gender, and the medical history of donors was available for 20 kidney cortex samples from CMFT Biobank. This data set was insufficient for robust assessment of any potential demographic covariates of MPPGK, as reported previously for MPPGL (Barter et al., 2008). The CMFT Biobank kidney cortex samples were from donors aged 43 to 83 years at the time of nephrectomy, which represents a subsection of the overall adult population, a trend consistent with previous studies (Scotcher et al., 2016b). Further data are therefore required, particularly for younger subjects, to investigate any potential relationship between MPPGK/CPPGK and demographic factors.

The average human CPPGK (53.3 mg/kidney cortex) was approximately two-thirds of the value reported for CPPGL (Cubitt et al., 2011). To the authors' knowledge, the potential contribution of microsomal GST isoforms within the liver homogenate was not accounted for in previous studies when GST was used as the cytosolic protein marker for liver. The estimated human S9 protein per gram of kidney cortex, based on the combined values of MPPGK and CPPGK, was $79.5 \mathrm{mg} / \mathrm{g}$ kidney cortex $(24 \% \mathrm{CV})$, which is lower than the corresponding value for liver (121 mg/g liver), as well as an estimated value of $93.5 \mathrm{mg} / \mathrm{g}$ kidney used previously for scaling ((Nishimuta et al., 2014), calculated from an MPPGK value of $12.8 \mathrm{mg} / \mathrm{g}$ kidney and liver cytosolic recovery of $80.7 \mathrm{mg} / \mathrm{g}$ liver).
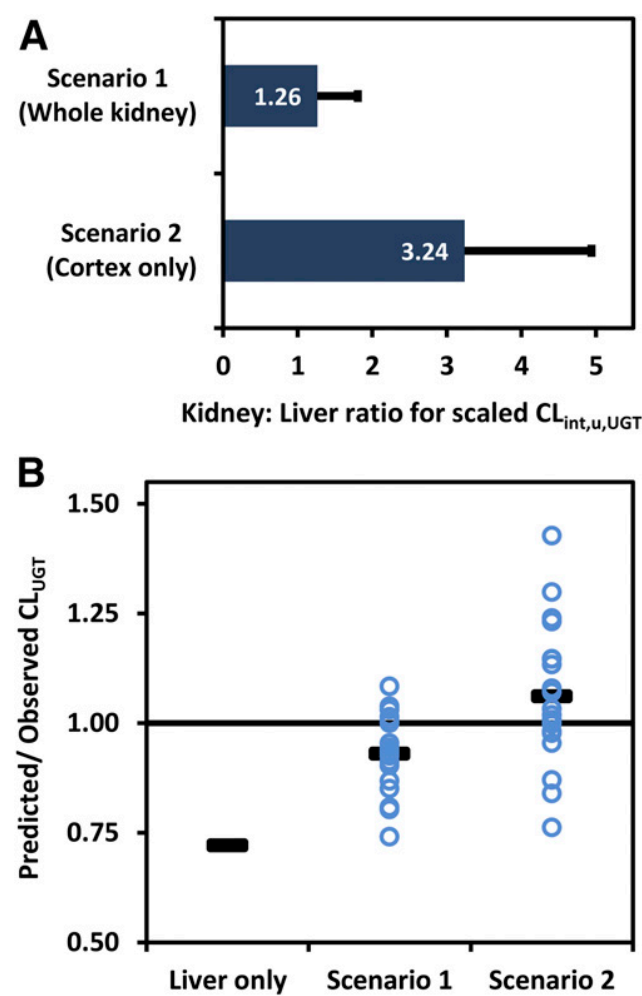

Fig. 7. IVIVE of mycophenolic acid clearance under two different scenarios. MPPGK, kidney weight, and blood flow parameters used for scaling and in the well stirred kidney model represented either the whole kidney (Scenario 1) or kidney cortex (Scenario 2); details are listed in Table 5. (A) Kidney: liver ratios of scaled mycophenolic acid $\mathrm{CL}_{\text {int, }, \mathrm{UGT}}(\mathrm{ml} / \mathrm{min} / \mathrm{g}$ tissue). Bars represent mean values; error bars represent the standard deviation. (B) Prediction accuracy of mycophenolic acid $\mathrm{CL}_{\mathrm{UGT}}$, considering either the hepatic glucuronidation alone or the sum of the hepatic and renal glucuronidation clearances. The contribution of renal glucuronidation was predicted using two scenarios. Individual (blue open circle) and mean (black line) data are shown $(n=20)$. Solid horizontal line represents line of unity.

\section{Impact of Updated MPPGK Scaling Factors on Prediction of Renal Metabolic Clearance}

As the cortex displays predominant UGT expression and greater blood flow relative to weight than medulla, it is likely that cortex has a predominant role in renal drug metabolism in vivo. For this reason, the renal cortex glucuronidation clearance of mycophenolic acid was estimated by modifying the kidney weight and renal blood flow parameters accordingly in the well stirred kidney model (Scenario 2) and compared with predictions based on assumptions of uniform kidney physiology (Scenario 1). A substantial difference was found between Scenario 1 and 2 for scaled $\mathrm{CL}_{\text {int,u,UGT,HKM, with a less pronounced }}$ difference in the IVIVE of the overall glucuronidation clearance. In the case of mycophenolic acid, each scenario resulted in adequate prediction accuracy of its $\mathrm{CL}_{\mathrm{UGT}}$ (Fig. 7B); however, scenarios differed in their estimated contribution of kidney glucuronidation relative to liver. These differences highlight the importance of knowing the source (cortex/medulla/ mixed) of microsomes being used for in vitro assays and applying the correct MPPGK scalar for IVIVE of renal drug metabolism data, namely, $11.1 \mathrm{mg} / \mathrm{g}$ of kidney for mixed kidney and $26.2 \mathrm{mg} / \mathrm{g}$ of kidney for the cortex. In addition, the source of microsomes used would limit which of the available kidney models are appropriate for prediction of in vivo metabolic clearance (Fig. 1). Conversely, in vitro data required to inform parameters of a specific kidney model should be generated using microsomes prepared from the appropriate region of kidney (Fig. 1).

Mycophenolic acid is an immunosuppressant for which therapeutic drug monitoring has been proposed owing to a narrow therapeutic 
window and pronounced interindividual variability in its pharmacokinetics and side effects (Dong et al., 2014). Variability of approximately $50 \%$ in its $\mathrm{CL}_{\text {int,u,UGT,HKM }}$ observed in the current study is consistent with the interindividual variability of clearance reported clinically. Several factors have been identified as covariates of mycophenolic acid pharmacokinetics in vivo, including SNPs in UGT1A9 (e.g., -440T > C) and 2B7 (e.g., -900G > A) (Picard et al., 2005; Fukuda et al., 2012). Of the SNPs investigated in the current study, the UGT2B7 -900G $>$ A was the only one linked with variability in mycophenolic acid in vitro

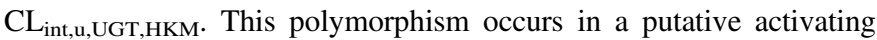
protein 1 binding site in the UGT2B7 promotor and could therefore affect the activity of the promotor ( $\mathrm{Hu}$ et al., 2014a), contributing to interindividual variability in mycophenolic acid renal glucuronidation observed in vitro.

In conclusion, MPPGK in dogs was characterized for the first time, in addition to microsomal recoveries obtained for the liver and intestinal samples from the same animals. MPPGK estimated from frozen dog samples was lower than MPPGL, but it was greater than MPPGI, with no direct correlations between scaling factors. Human MPPGK in kidney cortex, measured in 38 donors (mean: $26.2 \mathrm{mg} / \mathrm{g}$ kidney cortex; range: $9.0-42.6 \mathrm{mg} / \mathrm{g}$ kidney cortex) was on average 2-fold higher than the literature MPPGK value commonly used for IVIVE scaling of renal metabolism data. Human CPPGK was measured for the first time, with mean and range of 53.3 and 30.6-123.2 mg/g kidney cortex, respectively. The current study indicates that microsomal and cytosolic scaling factors need to correspond to the tissue source (i.e., mixed kidney or cortex) used to prepare the subcellular fractions for in vitro assays. Therefore, commercial providers of human kidney microsomes and cytosols are expected to explicitly state the tissue region used. In addition to using the MPPGK for cortex, the IVIVE of in vitro data obtained in cortex microsomes needs to account for differences in cortex weight and blood flow relative to the whole kidney. Mycophenolic acid case study highlighted the implications of refined scaling factors and appreciation of regional differences on the prediction of renal metabolism and its contribution to overall clearance.

\section{Acknowledgments}

The authors thank Dr. Oliver Hatley for sharing the dog intestine data and for useful scientific discussions; also, Sue Murby and Dr. David Hallifax (University of Manchester) for their assistance with the LC-MS/MS analysis; and Eleanor Savill for assisting in preparing this manuscript.

\section{Authorship Contributions}

Participated in research design: Scotcher, Jones, Rostami-Hodjegan, Galetin. Conducted experiments: Scotcher, Billington.

Contributed new reagents or analytic tools: J. Brown, C.D.A. Brown.

Performed data analysis: Scotcher, Rostami-Hodjegan, Galetin.

Wrote or contributed to the writing of the manuscript: Scotcher, J. Brown, Jones, C.D.A. Brown, Rostami-Hodjegan, Galetin.

\section{References}

Al-Jahdari WS, Yamamoto K, Hiraoka H, Nakamura K, Goto F, and Horiuchi R (2006) Prediction of total propofol clearance based on enzyme activities in microsomes from human kidney and liver. Eur J Clin Pharmacol 62:527-533.

Barter ZE, Bayliss MK, Beaune PH, Boobis AR, Carlile DJ, Edwards RJ, Houston JB, Lake BG, Lipscomb JC, Pelkonen OR, et al. (2007) Scaling factors for the extrapolation of in vivo metabolic drug clearance from in vitro data: reaching a consensus on values of human microsomal protein and hepatocellularity per gram of liver. Curr Drug Metab 8 $33-45$.

Barter ZE, Chowdry JE, Harlow JR, Snawder JE, Lipscomb JC, and Rostami-Hodjegan A (2008) Covariation of human microsomal protein per gram of liver with age: absence of influence of operator and sample storage may justify interlaboratory data pooling. Drug Metab Dispos 36: 2405-2409.

Bernard O and Guillemette C (2004) The main role of UGT1A9 in the hepatic metabolism of mycophenolic acid and the effects of naturally occurring variants. Drug Metab Dispos 32 $775-778$.
Burke MD and Orrenius S (1979) Isolation and comparison of endoplasmic reticulum membranes and their mixed function oxidase activities from mammalian extrahepatic tissues. Pharmacol Ther 7:549-599.

Cubitt HE, Houston JB, and Galetin A (2009) Relative importance of intestinal and hepatic glucuronidation-impact on the prediction of drug clearance. Pharm Res 26:1073-1083.

Cubitt HE, Houston JB, and Galetin A (2011) Prediction of human drug clearance by multiple metabolic pathways: integration of hepatic and intestinal microsomal and cytosolic data. Drug Metab Dispos 39:864-873

Dong M, Fukuda T, and Vinks AA (2014) Optimization of mycophenolic acid therapy using clinical pharmacometrics. Drug Metab Pharmacokinet 29:4-11.

Estabrook RW and Werringloer J (1978) The measurement of difference spectra: application to the cytochromes of microsomes. Methods Enzymol 52:212-220.

Fukuda T, Goebel J, Cox S, Maseck D, Zhang K, Sherbotie JR, Ellis EN, James LP, Ward RM, and Vinks AA (2012) UGT1A9, UGT2B7, and MRP2 genotypes can predict mycophenolic acid pharmacokinetic variability in pediatric kidney transplant recipients. Ther Drug Monit 34: 671-679.

Gertz M, Harrison A, Houston JB, and Galetin A (2010) Prediction of human intestinal first-pass metabolism of 25 CYP3A substrates from in vitro clearance and permeability data. Drug Metab Dispos 38:1147-1158.

Gill KL, Houston JB, and Galetin A (2012) Characterization of in vitro glucuronidation clearance of a range of drugs in human kidney microsomes: comparison with liver and intestinal glucuronidation and impact of albumin. Drug Metab Dispos 40:825-835.

Hatley OJD, Jones CR, Galetin A, and Rostami-Hodjegan A (2017) Optimisation of intestinal microsomal preparation in the rat: A systematic approach to assess the influence of various methodologies on metabolic activity and scaling factors. Biopharm Drug Dispos (in press).

Hayes JD and Pulford DJ (1995) The glutathione S-transferase supergene family: regulation of GST and the contribution of the isoenzymes to cancer chemoprotection and drug resistance. Crit Rev Biochem Mol Biol 30:445-600.

Heikkinen AT, Friedlein A, Lamerz J, Jakob P, Cutler P, Fowler S, Williamson T, Tolando R, Lave T, and Parrott N (2012) Mass spectrometry-based quantification of CYP enzymes to establish in vitro/in vivo scaling factors for intestinal and hepatic metabolism in beagle dog. Pharm Res 29:1832-1842

Heikkinen AT, Friedlein A, Matondo M, Hatley OJ, Petsalo A, Juvonen R, Galetin A, RostamiHodjegan A, Aebersold R, Lamerz J, et al. (2015) Quantitative ADME proteomics - CYP and UGT enzymes in the Beagle dog liver and intestine. Pharm Res 32:74-90.

Houston JB (1994) Utility of in vitro drug metabolism data in predicting in vivo metabolic clearance. Biochem Pharmacol 47:1469-1479.

Houston JB and Galetin A (2008) Methods for predicting in vivo pharmacokinetics using data from in vitro assays. Curr Drug Metab 9:940-951.

Hu DG, Meech R, Lu L, McKinnon RA, and Mackenzie PI (2014a) Polymorphisms and haplotypes of the UDP-glucuronosyltransferase 2B7 gene promoter. Drug Metab Dispos 42:854-862.

Hu DG, Meech R, McKinnon RA, and Mackenzie PI (2014b) Transcriptional regulation of human UDP-glucuronosyltransferase genes. Drug Metab Rev 46:421-458.

Jakobsson SV (1974) Subfractionation and properties of rat kidney cortex microsomal fraction. Exp Cell Res 84:319-334.

Jakobsson SV and Cinti DL (1973) Studies on the cytochrome P-450-containing mono-oxygenase system in human kidney cortex microsomes. J Pharmacol Exp Ther 185:226-234.

Ji Y, Toader V, and Bennett BM (2002) Regulation of microsomal and cytosolic glutathione S-transferase activities by S-nitrosylation. Biochem Pharmacol 63:1397-1404.

Johannesen KA and DePierre JW (1978) Measurement of cytochrome P-450 in the presence of large amounts of contaminating hemoglobin and methemoglobin. Anal Biochem 86: $725-732$.

Kartenbeck J, Jarasch ED, and Franke WW (1973) Nuclear membranes from mammalian liver. VI. Glucose-6-phosphatase in rat liver, a cytochemical and biochemical study. Exp Cell Res 81: $175-194$.

Kilford PJ, Stringer R, Sohal B, Houston JB, and Galetin A (2009) Prediction of drug clearance by glucuronidation from in vitro data: use of combined cytochrome P450 and UDPglucuronosyltransferase cofactors in alamethicin-activated human liver microsomes. Drug Metab Dispos 37:82-89.

Knights KM, Spencer SM, Fallon JK, Chau N, Smith PC, and Miners JO (2016) Scaling factors for the in vitro-in vivo extrapolation (IV-IVE) of renal drug and xenobiotic glucuronidation clearance. $\mathrm{Br}$ J Clin Pharmacol 81:1153-1164.

Lerman LO, Flickinger AL, Sheedy, 2ndPF, and Turner ST (1996) Reproducibility of human kidney perfusion and volume determinations with electron beam computed tomography. Invest Radiol 31:204-210.

Lin B, Morris DW, and Chou JY (1997) The role of HNF1 $\alpha$, HNF3 $\gamma$, and cyclic AMP in glucose6-phosphatase gene activation. Biochemistry 36:14096-14106.

Litterst CL, Mimnaugh EG, Reagan RL, and Gram TE (1975) Comparison of in vitro drug metabolism by lung, liver, and kidney of several common laboratory species. Drug Metab Dispos 3:259-265.

Matsubara T, Koike M, Touchi A, Tochino Y, and Sugeno K (1976) Quantitative determination of cytochrome P-450 in rat liver homogenate. Anal Biochem 75:596-603.

Morgenstern R, Lundqvist G, Andersson G, Balk L, and DePierre JW (1984) The distribution of microsomal glutathione transferase among different organelles, different organs, and different organisms. Biochem Pharmacol 33:3609-3614.

Nishimuta H, Houston JB, and Galetin A (2014) Hepatic, intestinal, renal, and plasma hydrolysis of prodrugs in human, cynomolgus monkey, dog, and rat: implications for in vitro-in vivo extrapolation of clearance of prodrugs. Drug Metab Dispos 42:1522-1531.

Nordlie RC (1979) Multifunctional glucose-6-phosphatase: cellular biology. Life Sci 24: 2397-2404.

Nordlie RC and Arion WJ (1966) [111] Glucose-6-phosphatase. Methods Enzymol 9:619-625.

Ohno Y, Kawanishi T, Takahashi A, Kasuya Y, and Omori Y (1982) A new device for the determination of microsomal cytochrome $\mathrm{P}-450$ in renal tissue preparations from various species contaminated with mitochondria and hemoglobin. Jpn J Pharmacol 32:679-688.

Orellana M, Araya J, Guajardo V, and Rodrigo R (2002) Modulation of cytochrome P450 activity in the kidney of rats following long-term red wine exposure. Comp Biochem Physiol C Toxicol Pharmacol 132:399-405.

Pearce RE, McIntyre CJ, Madan A, Sanzgiri U, Draper AJ, Bullock PL, Cook DC, Burton LA, Latham J, Nevins C, et al. (1996) Effects of freezing, thawing, and storing human liver microsomes on cytochrome P450 activity. Arch Biochem Biophys 331:145-169. 
Picard N, Ratanasavanh D, Prémaud A, Le Meur Y, and Marquet P (2005) Identification of the UDP-glucuronosyltransferase isoforms involved in mycophenolic acid phase II metabolism. Drug Metab Dispos 33:139-146.

Prabhu KS, Reddy PV, Jones EC, Liken AD, and Reddy CC (2004) Characterization of a class alpha glutathione-S-transferase with glutathione peroxidase activity in human liver microsomes. Arch Biochem Biophys 424:72-80.

Prausa SE, Fukuda T, Maseck D, Curtsinger KL, Liu C, Zhang K, Nick TG, Sherbotie JR, Ellis EN, Goebel J, et al. (2009) UGT genotype may contribute to adverse events following medication with mycophenolate mofetil in pediatric kidney transplant recipients. Clin Pharmacol Ther $\mathbf{8 5}$ 495-500.

Rajas F, Gautier A, Bady I, Montano S, and Mithieux G (2002) Polyunsaturated fatty acyl coenzyme A suppress the glucose-6-phosphatase promoter activity by modulating the DNA binding of hepatocyte nuclear factor $4 \alpha$. J Biol Chem 277:15736-15744.

Ramírez J, Mirkov S, Zhang W, Chen P, Das S, Liu W, Ratain MJ, and Innocenti F (2008) Hepatocyte nuclear factor-1 alpha is associated with UGT1A1, UGT1A9 and UGT2B7 mRNA expression in human liver. Pharmacogenomics $J$ 8:152-161.

Säll C, Houston JB, and Galetin A (2012) A comprehensive assessment of repaglinide metabolic pathways: impact of choice of in vitro system and relative enzyme contribution to in vitro clearance. Drug Metab Dispos 40:1279-1289.

Sausen PJ and Elfarra AA (1990) Cysteine conjugate S-oxidase: characterization of a novel enzymatic activity in rat hepatic and renal microsomes. J Biol Chem 265:6139-6145.

Scotcher D, Jones C, Posada M, Galetin A, and Rostami-Hodjegan A (2016a) Key to opening kidney for in vitro-in vivo extrapolation entrance in health and disease. Part II: Mechanistic models and in vitro-in vivo extrapolation. AAPS J 18:1082-1094.
Scotcher D, Jones C, Posada M, Rostami-Hodjegan A, and Galetin A (2016b) Key to opening kidney for in vitro-in vivo extrapolation entrance in health and disease. Part I: In vitro systems and physiological data. AAPS J 18:1067-1081.

Simić T, Mimić-Oka J, Ille K, Dragicević D, and Savić-Radojević A (2003) Glutathione S-transferase isoenzyme profile in non-tumor and tumor human kidney tissue. World J Urol 20:385-391.

Simic T, Mimic-Oka J, Ille K, Savic-Radojevic A, and Reljic Z (2001) Isoenzyme profile of glutathione S-transferases in human kidney. Urol Res 29:38-44.

Smith R, Jones RD, Ballard PG, and Griffiths HH (2008) Determination of microsome and hepatocyte scaling factors for in vitro/in vivo extrapolation in the rat and dog. Xenobiotica 38 : $1386-1398$.

Song W, Yu L, and Peng Z (2015) Targeted label-free approach for quantification of epoxide hydrolase and glutathione transferases in microsomes. Anal Biochem 478:8-13.

Taussky HH and Shorr E (1953) A microcolorimetric method for the determination of inorganic phosphorus. J Biol Chem 202:675-685.

Vallée J-P, Lazeyras F, Khan HG, and Terrier F (2000) Absolute renal blood flow quantification by dynamic MRI and Gd-DTPA. Eur Radiol 10:1245-1252.

Address correspondence to: Dr. A. Galetin, Centre for Applied Pharmacokinetic Research, School of Health Sciences, The University of Manchester, Stopford Building, Oxford Road, Manchester, M13 9PT, UK. E-mail: Aleksandra.Galetin@ manchester.ac.uk 